\title{
Working
}

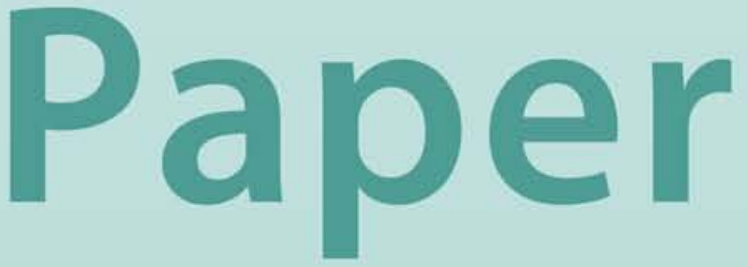




\section{Taxes and Tradable Permits as Instruments for Controlling Pollution: Theory and Practice}

John Norregaard and Valerie ReppelinHill 
IMF Working Paper

(C) 2000 International Monetary Fund
This is a Working Paper and the author(s) would welcome any comments on the present text. Citations should refer to a Working Paper of the Intemational Monetary Fund. The views expressed are those of the author(s) and do not necessarily represent those of the Fund.

$\mathrm{WP} / 00 / 13$

INTERNATIONAL MONETARY FUND

Fiscal Affairs Department

\title{
Taxes and Tradable Permits as Instruments for Controlling Pollution: Theory and Practice
}

\author{
Prepared by John Norregaard and Valérie Reppelin-Hill ${ }^{\mathbb{1}}$ \\ Authorized for distribution by Liam Ebrill
}

January 2000

\begin{abstract}
This paper examines the relative merits of two dominant economic instruments for reducing pollution- "green" taxes and tradable permits. Theoretically, the two instruments share many similarities, and on balance, neither seems preferable to the other. In practice, however, most countries have relied more on taxes than on permits to control pollution. The analysis suggests a number of lessons to be learned from country experiences regarding the design and implementation of both instruments. While many, particularly European countries, currently have long-term programs involving environmental taxes, a willingness to experiment with tradable permits seems to be growing, especially given the Kyoto protocol emission targets.
\end{abstract}

JEL Classification Numbers: H2O, Q00

Keywords: Environmental taxes; tradable permits

Author's E-Mail Address: jnorregaard@imf.org, vreppelin@imf.org

\footnotetext{
${ }^{1}$ The authors are staff members of the IMF's Fiscal Affairs Department. They would like to thank Liam Ebrill, Angelo Faria, and Harald Hirschhofer for useful comments.
} 


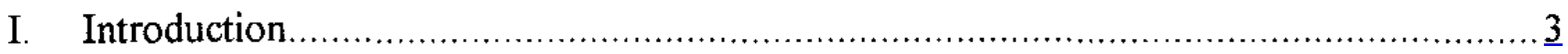

II. Emission Taxes versus Tradable Permits: Review of the Literature .......................... $\underline{5}$

A. The Equivalence of Emission Taxes and Tradable Permits in a First-Best World ........................................................................... 5

B. Emission Taxes and Tradable Permits in a Second-Best World ....................... 7

III. Environmental Taxes Versus Tradable Permits: Review of the Country

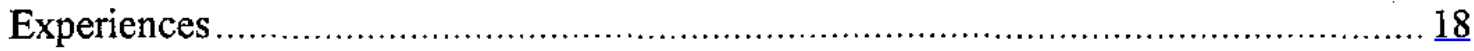

A. Broad Overview of OECD Experience with Environmental Taxes .................. $\underline{18}$

B. Limited Experience with Tradable Permits........................................... 27

IV. The Scope for Taxes and Tradable Permits: Tentative Conclusions ......................... 31

\section{Tables}

1. Summary of Efficiency Considerations and Market Structure .............................. 11

2. Summary of the Basic Criteria for the Choice of Policy Instruments..................... 19

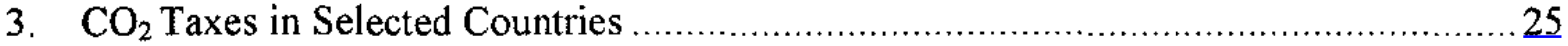

4. Summary of Main Tradable Permits Applications in OECD Countries ......................28

Boxes

1. Pollution Control when Marginal Abatement Costs are Uncertain ......................... $\underline{8}$

2. Defining Environmental Taxes, Charges, and Other Instruments ........................20

\section{Figures}

1. Emission Taxes and Tradable Permits in a First-Best World ................................ $\underline{6}$

2. Pollution Control when the MD Function is Flatter than the MAC Function ............... $\underline{8}$

3. Pollution Control when the MD Function is Steeper than the MAC Function .............. $\underline{8}$

4. Revenues from Environmentally Related Taxes in Percent of Total Tax Revenue

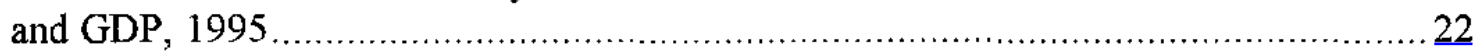

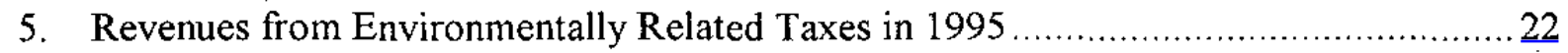

Appendixes

I. Country Experiences with Environmental Taxes: The Ecotax Leaders..................... $\underline{34}$

II. Country Experiences with Tradable Permits Systems ..................................... 40

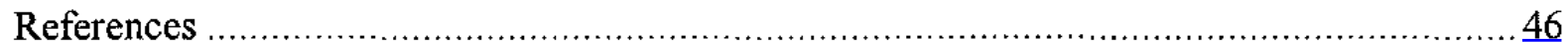




\section{INTRODUCTION}

Since Pigou's (1920) seminal contribution on the efficiency enhancing use of taxes to correct for negative externalities, the choice of instruments for environmental policy has been extensively debated. The environmental economics literature has drawn a sharp distinction between command and control approaches (CAC) and the use of market-based incentives (MBI). While on theoretical grounds, MBIs are generally preferred because they are more cost effective in practice, CAC policies have been predominantly used. This apparent contrast was highlighted at the time of the environmental revolution in the late $1960 \mathrm{~s}$ and early 1970s. Oates (1999) suggests three explanations for this. First, at the time, there was no constituency to whom the economists' view had much appeal (i.e., environmentalists were decidedly hostile, industry was not very sympathetic and regulators were less than enthusiastic about discarding traditional methods of regulatory controls for a largely untried system of taxes on pollution). Second the state of environmental economics in the late $1960 \mathrm{~s}$ and early 1970 s did not go much beyond the general conceptual level. Third, there seemed to be a pervasive ignorance of the economic approach to environmental policy outside the economics profession itself. In recent years, however, economic instruments have played an ever-increasing role in environmental policymaking, reflecting their perceived superiority vis-à-vis CAC policies. And while the early discussion focused almost exclusively on the tax approach, the scope has broadened to include tradable permits. The discussion has taken on a new importance following the agreement in December 1997 to reduce emissions of "greenhouse gases" under the Kyoto Protocol.

Indeed, on December 10, 1997, 160 nations reached a historic agreement in Kyoto, Japan, on limiting emissions of carbon dioxide $\left(\mathrm{CO}_{2}\right)$ and other "greenhouse gases." The Kyoto Protocol calls for the industrialized nations-the so-called Annex I countries-to reduce their average emissions over the period 2008-2012 to about 5 percent below 1990 levels. The United States pledged to reduce its emissions by 7 percent below 1990, slightly less than the European Union ( 8 percent) and slightly more than Japan ( 6 percent). The Protocol permits some industrialized nations to increase modestly their emissions in the short run, while making special provisions for the members of the former Soviet Union. None of the developing countries, including those with large and growing emissions such as India and China, is required to limit their emissions. ${ }^{2}$

The agreement reached in Kyoto sets the stage for lengthy and complex preratification discussions both at the national and international levels, as the proposed targets are likely to

${ }^{2}$ The Protocol implicitly recognizes that developing countries may need additional time to meet the requirements of the agreement, taking into account potential technical and economic constraints. 
impose significant costs on the global economy. ${ }^{3}$ A key issue is the appropriate international distribution of these costs. While recent public opinion polls indicate increased concern about climate change and some willingness to share burdens to curb greenhouse gas emissions, there is no compelling evidence that the public is ready to accept significant increases in energy prices or other costs. It is thus still an open question whether countries will be willing to ratify the Protocol.

An important first step in fostering a productive debate and increased public awareness over the Protocol is a better understanding of its benefits and costs. Even after questions about the Protocol itself are settled, domestic policy options for achieving the targets and timetables will still require more thorough consideration, as clearly the magnitude of the costs will depend on the domestic policies used. No agreement yet exists on this policy menu. However, much of the debate has centered on the use of MBI mechanisms as opposed to CACs, precisely because of the large potential cost savings that MBIs offer. ${ }^{4}$ Among MBIs, the basic choice faced by policymakers concerns price-based versus quantity-based instruments or, in other words, environmental taxes versus tradable permits.

This paper discusses the choice between these two economic instruments. The first part reviews the theoretical literature, starting from the Pigouvian tradition with the aim of clarifying the contribution of economic analysis to the environmental policy debate. We show that, in a first-best setting, Pigouvian taxes and tradable permits are equivalent. However, this fundamental result ignores crucial features of the practical world. We then proceed to review the more recent literature on the choice of environmental policy in a second-best setting. To do this, we define a set of criteria along which the two instruments may usefully be compared, and we show that no instrument is clearly preferred to the other. The second part of the paper reviews the actual use of the two instruments, mainly in the Organization for Economic Cooperation and Development (OECD) countries. In sharp contrast to the apparent similarities of the two instruments discussed in Part I, in practice, countries have relied substantially more on taxes than on permits to control pollution (with the notable exception of the United States). Yet willingness to experiment with tradable permits seems to be expanding. We discuss issues in this section that may arise in a practical setting and that are typically not discussed in most theoretical studies. Finally, we suggest broad conclusions with respect to the implementation of both types of instrument. Specific country experiences are discussed at length in the appendixes.

\footnotetext{
${ }^{3}$ For example, the limit agreed to by the United States implies a reduction by about one-third compared to the estimated level of $\mathrm{CO}_{2}$ emissions at the end of the next decade in the absence of such measures.

${ }^{4}$ Tietenberg (1985), in a review of several studies, found that the potential magnitudes of these cost savings range from 50 to 90 percent. More recent studies by O'Ryan (1996) and Klaassen (1996) show quite similar results.
} 


\section{EMISSION TAXes VeRSUS TRADABLE PERMits: ReVIEW OF THE LITERATURE}

Pollution taxes and marketable pollution permits are, in principle, very similar policy instruments. Both rely on price signals and incentives for emitters to reduce the costs they impose on society. Pigouvian taxes (Pigou, 1920) involve setting a charge per unit of emissions equal to the total value of the damage caused by an extra unit of emissions. This signals the true social costs to the emitter, who then has a financial incentive to reduce emissions up to the point where the profit/loss due to a unit reduction in emissions is equal to the damage involved. In a system of marketable permits, the regulatory authority allocates permits equal to a determined aggregate quantity of emissions, possibly, but not necessarily, through an auction. The permits are tenable for a defined period (or perhaps indefinitely) and tradable. Trading of permits among emitters will, enforcement problems apart, establish a market-determined price of emissions which, as in the case of a tax, will signal damage costs and give emitters financial incentives to respond by reducing emissions. The following subsection demonstrates the efficiency equivalence of the two instruments in a first-best setting, while the subsequent subsection discusses second-best scenarios and compares the two instruments along a series of relevant criteria.

\section{A. The Equivalence of Emission Taxes and Tradable Permits in a First-Best World}

To establish a basis for comparison among relative policy instruments, the traditional literature often relies on the following assumptions: (1) that the same amount of emissions from different sources have equal external costs; (2) that raising revenues through environmental policies is not in itself costly-in other words, the literature ignores possible interactions with other markets and/or other revenue sources; (3) that there is no uncertainty about the costs and benefits of pollution control; and (4) that a competitive structure prevails. We will refer to this set of assumptions as the first-best world scenario. In this setting, it is easy to show that emission taxes and tradable permits are, in a fundamental sense, equivalent (e.g., they achieve the same level of emissions with minimum levels of abatement costs).

Figure 1 illustrates this outcome.

The marginal damage (MD) function specifies the damages associated with an additional unit of pollution. It is typically assumed to be increasing, for example, as the level of pollution becomes larger, the damages associated with a marginal unit of pollution become larger (possibly because dilution in the atmosphere is less effective).

The marginal abatement cost (MAC) function specifies the costs associated with the reduction of an additional unit of emissions. These costs include the costs of the labor, capital, and energy needed to lessen the emissions of pollution associated with particular levels of production. These costs may also take the form of opportunity costs from reducing the levels of production. Generally, firms can reduce emissions by four means: (1) reducing output; (2) treating or intercepting emissions before they enter the environment (end-of-pipe treatment); (3) changing input; and (4) changing production processes. The literature on pollution control makes no specific assumption as to which of the four options firms will 
Figure 1. Emission Taxes and Tradable Permits in a First-Best World

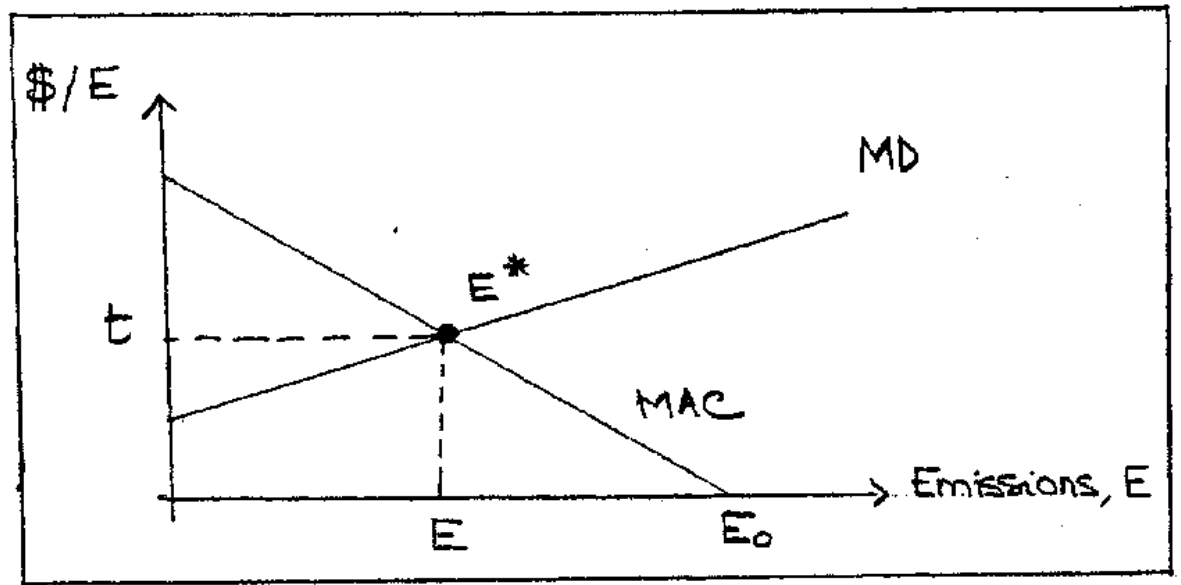

typically choose (firms will choose whichever option minimizes costs and that will depend on the specific pollutant considered). However, the marginal abatement cost function is generally assumed to be decreasing indicating that as firms reduce pollution below the level they each privately regard as optimal and toward zero, the cost of abatement increases (as the cheaper alternatives are exhausted, more expensive steps must be taken to further reduce pollution).

$\mathrm{E}_{0}$ corresponds to the level of emissions that would prevail in the absence of emission-control policy (firms have no incentive to abate and MAC equals zero). $\mathrm{E}^{*}$ corresponds to the optimal level of emissions, where the marginal damage of an extra unit of emissions equals the marginal costs of abating one extra unit of emissions. $E^{*}$ can clearly be achieved by imposing an emission tax equal to $t$ upon each unit of emissions; polluters would then find it more costly to pay the tax than to adopt measures that reduce their emissions from $E_{0}$ to $E$. Similarly, the optimal solution can be attained if the environmental control agency issues a quantity of permits just sufficient to lead to a level of emissions equal to $E$. In the specific case considered, the permits must allow $\left(\mathrm{E}_{0}-\mathrm{E}\right)$ units of emissions. Assuming that the market for permits is competitive, the price of a permit will be bid up exactly to $t$, that is, to the corresponding marginal cleanup cost. Thus, under the specified conditions, the two approaches will lead to the same outcome, reducing emissions to the optimal level at minimum cost.

While this basic equivalence holds in principle, the two approaches exhibit some important differences in a practical policy setting, when the basic underlying assumptions are relaxed to conform more closely to conditions that are likely to prevail in the real world. The following section discusses the choice of policy instruments in a second-best world and suggests a set of criteria along which the emission taxes and tradable permits may be usefully compared. 


\section{B. Emission Taxes and Tradable Permits in a Second-Best World}

Bohm and Russell (1985) suggest comparing alternative instruments to control pollution along several main dimensions: information intensity, efficiency, ease of monitoring and enforcement, flexibility in the face of economic change, dynamic incentives, and political considerations. We will also discuss revenue-raising potentials as an important additional criterion.

\section{Information intensity}

Information intensity is defined as the amount of information that the pollution control agency must have in order to operate the system in question. Clearly, in order to achieve the optimal level of emissions, the regulator must have information on firms' marginal abatement costs and the marginal damage from emissions. Hence the information requirements are identical, whether using a system of emission taxes and/or tradable permits.

When there is uncertainty either about the marginal benefits or the marginal costs of abatement, the socially optimal level of emissions will typically not be achieved. The goal of the policy then is to minimize efficiency losses. An important result is that when the marginal costs of abatement are known, uncertainty about the benefits does not favor one policy instrument over the other. Firms abate only on the basis of their costs and of the policy instrument, which are both known. So, even if the benefits deviate from expected levels, the abatement level and the efficiency losses will be exactly the same for the emission tax as for the tradable permits system (see Baumol and Oates, 1988).

When abatement costs are uncertain, producers are assumed to have information, which the planner does not have and their actions may therefore differ from those the planner had expected. Weitzman (1974) and White and Wittman (1983) were among the first to carry out a rigorous analysis of whether an emission tax or a system of tradable permits would be the best policy in this situation of asymmetric information. They show that taxes minimize expost efficiency losses if the marginal cost function is steeper than the marginal damage function, while tradable permits are better if the damage function is steeper. It is therefore the relative steepness of the marginal damage and marginal abatement cost curves that determines which of the two policy instruments promises the smaller efficiency losses.

The basic idea is straightforward (see Box 1). When the marginal benefit curve is relatively steeper (this would represent a case where the benefits from changes in environmental quality vary dramatically with changes in pollution levels), one wants to ensure reliable and precise control over the quantity of emissions (to avoid crucial threshold effects for instance). In such instances, tradable permits are preferred. On the other hand, when the marginal cost curve is steeper, for example, deviation in emissions are less costly than unexpected marginal abatement costs, the more pressing danger from a policymaking perspective is one of excessive cost. In this setting, the danger is greater under the permits instrument for, if the supply of permits is set too low, excessive compliance costs will be set upon firms. With the emission tax, the danger is avoided since firms can always opt to pay the tax and avoid the 


\section{Box 1. Pollution Control when Marginal Abatement Costs are Uncertain}

Figures 2 and 3 below illustrate the efficiency losses associated with an emission tax and a system of tradable permits when MACs are uncertain. Let MAC $^{\boldsymbol{A}}$ represent the regulator's anticipated MAC while MAC ${ }^{\mathrm{T}}$ represents the firm's true MAC. Under an emission tax, the regulator would set the tax equal to $t$, where MDs equal the anticipated MAC, which would result in a level of emissions equal to $\mathbf{E}^{\mathfrak{t}}$, where the MDs are equal to the firm's true MAC. The efficiency losses resulting from the use of the emission tax are represented by area $\mathrm{E}^{*} \mathrm{AB}$. Under a permits system, the regulator would issue a permit amount equal to $E^{p}$. The efficiency losses under this scenario are equal to area $E^{*} D C$. Figures 2 and 3 illustrate that when the MD is relatively flatter, the emission tax yield lower efficiency losses whereas when the MD is relatively steeper, the results are reversed and it is the permits system that generates lower efficiency losses.

Figure 2. Pollution Control when the MD Function is Flatter than the MAC Function

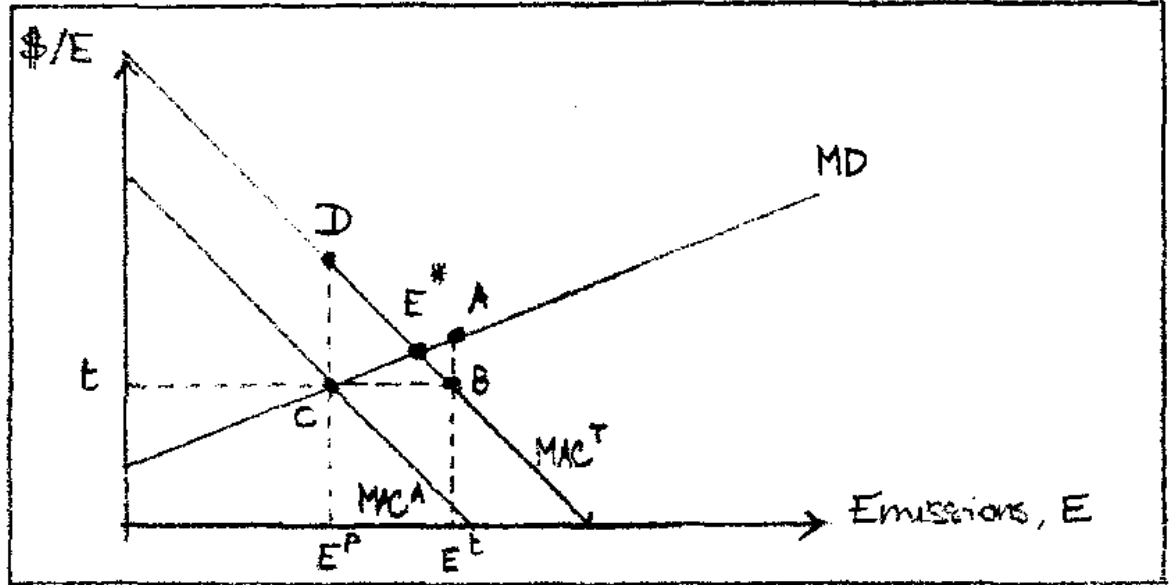

Figure 3. Pollution Control when the MD Function is Steeper than the MAC Function

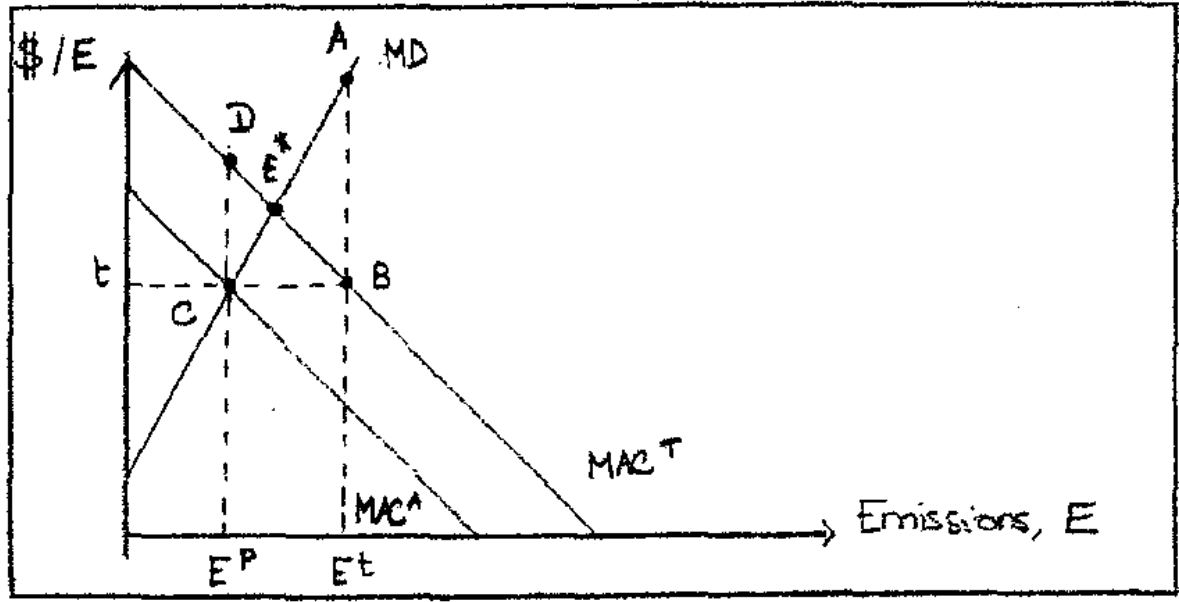


more costly control activities to reduce emissions.

What can we say about the relative steepness of the marginal damage curve relative to the steepness of the marginal abatement cost curve? In general, not much. Baumol and Oates (1988) argue that in real world situations, both marginal abatement costs and marginal damages are unlikely to be known with certainty by the regulator who is vulnerable to the provision of biased information by interested parties. In light of these difficulties, the literature suggests that policy instead should aim at achieving predetermined aggregate emission standards (however defined) in a least-cost manner (e.g., minimizing total abatement costs). Under this second-best scenario, marketable permits seem to have a considerable advantage over emission taxes, since the regulatory target is automatically built into the instrument being used and no additional information is needed. In order to attain the same target using taxes, the regulator needs some information on firms' marginal abatement costs. In the absence of such information, the authority may have to alter the tax in a process of trial-and-error iterations until the targeted level of emissions has been reached.

\section{Efficiency under noncompetitive market structure}

Efficiency is defined as the ability of an instrument to reduce emissions to a predetermined level at minimum abatement costs. This dimension is almost always interpreted in the literature in a static sense (assuming fixed environmental goals and fixed technology and allowing only for the first round of reactions to the respective instruments). We will also limit ourselves to static considerations in this section but will consider dynamic incentives in a latter section.

As noted earlier, in a first-best setting, the efficiency equivalence of emission taxes and tradable permits is well established. In the previous section, we discussed efficiency considerations under uncertainty. In this section, we assess how the efficiency properties of the two instruments are affected when one allows for noncompetitive market structure.

In the case of noncompetitive market structure, there are two sources of market failure: pollution externalities and market power. The first best solution to achieve efficient resource use would require the use of two instruments to address each failure separately (e.g., a subsidy on output to correct for market power and an emission tax and/or a system of tradable permits to correct the pollution externality). But can the environmental instrument alone correct for both sources of market failure?

In general, when the output market is not assumed to be perfectly competitive, neither emission taxes nor tradable permits achieve the social optimum. Buchanan (1969) considers the most simple case, the taxation of a monopolist polluter, and argues that a Pigouvian tax is likely to generate welfare losses by reducing output further in a situation where the monopoly's output is less than optimal already. Analyzing general control instruments, Burrows (1981) points out that the risks that pollution taxes will increase welfare losses rise 
as the importance of output reduction from abatement rises; equivalently, the risks get less as the importance of process switching (end of the pipe purification) rises. ${ }^{5}$ The problem of calculating a "second-best fee" then weighs these needs against each other by combining a Pigouvian tax and a subsidy on output. ${ }^{6}$ Similar considerations can be made for market powers other than monopoly. ${ }^{7}$ Hence, the literature appears to suggest that the social optimum can be achieved by a suitably adjusted "Pigouvian" tax, although, as Requate (1993) points out, the argument holds only when firms are assumed to be identical (e.g., with similar pollution technology). Pigouvian taxes fail to achieve first-best outcomes when firms have different pollution technologies (in such instances, the social optimum can only be reached through firm-specific emission taxes).

Malueg (1990) considers the distribution of permits in a Cournot Oligopoly on the output market, and shows that the social optimum cannot be achieved either. Permits fail to achieve first-best because they encourage firms to collude. Given that neither an emission tax nor a system of tradable permits can achieve the social optimum, the question is whether in general terms one of the two policies is less inefficient. Requate (1993) argues that although no policy can be said to be superior to the other in all cases, the permits policy yields a higher welfare for a considerable range of parameters. In particular, if one firm's technology is globally inefficient, meaning that the firm should not produce in a social optimum, this inefficient firm will never produce under a permits system, regardless of how the permits are initially allocated. The optimal emission tax, on the other hand, does not always induce the inefficient firm to close down.

When dealing with tradable permits, however, the danger of market power is more prevalent in the permits market, since when firms behave as price setters-whether as sellers or buyers, many of the potential benefits of a tradable permits system will be lost (see Koustaal, 1997 and Xepapadeas, 1997, among others). For this reason, the potential for market power on the

${ }^{5}$ In this case, there are two sources of market failure that need to be addressed, namely, pollution externalities and market power characterized by a level of output that is less than optimal. Any instruments to correct for the environmental externality will encourage firms to reduce emissions. And to the extent that emission reductions are accompanied by reductions in output, the second type of market failure (e.g., suboptimal output levels) will be exacerbated and hence some welfare losses will occur. This risk is reduced when emissions reductions can be achieved through other means (end-of-pipe treatment, and the like).

${ }^{6}$ This sum collapses to the familiar Pigouvian tax if the industry is competitive, and it will equal zero if, as Buchanan suggests, the two effects cancel each other.

${ }^{7}$ In the case of an oligopoly for instance (see Ebert, 1992), the derivation of the second best fee would depend on the behavioral assumptions about the firms, but would essentially incorporate the same trade-off between the concerns of market power and excessive pollution. 
permits market has long been recognized as a disadvantage of tradable permits, relative to other MBIs such as taxes, for instance. When is market power most likely to occur? Clearly it depends on the degree of concentration on the permits market. Harrison (1999) presents estimates of the extent of concentration of emission sources in the United States which suggest that the greatest potential for market power would be in a market for permits for particulate matter, followed by $\mathrm{SO}_{2}$ and $\mathrm{CO}$. Indeed, since the effect of the former are quite localized, any program for particulate permits would have to be local in nature. This is also true for water pollutants since the environmental problem is localized and thus the permits market is likely to be spatially restricted (see Misiolek and Elder, 1989, Lyon, 1982, and Hahn, 1989). The potential for market power is also a function of the sectoral scope of the permits market. For instance, in the United States $\mathrm{SO}_{2}$ program, only electricity generators were included and not other sources. As a consequence, very few firms dominated permits trades. In 1995 and 1996, over 75 percent of all interutility purchases of permits were bought by one firm, Illinois Power (Ellerman and others, 1996).

There is, unfortunately, little empirical evidence of the extent to which market power is a problem in existing tradable permits systems. However, firms themselves clearly perceive the danger. For instance, in the case of $\mathrm{SO}_{2}$ permits, utilities in fast-growing states advocated that at least some of the permits be auctioned - even though this would appear to have adverse effect for them in financial terms, because of concerns that utilities in other states would exploit the market to their advantage (Joskow and Schmalensee, 1998). This fear was also behind the concerns of small firms advocating an auctioned permits allocation for the Regional Clean Air Incentives Market (RECLAIM) system, even though it would not appear to be in their financial interest (Polesetsky, 1995). Table 1 below summarizes the main findings of our discussion.

Table 1. Summary of Efficiency Considerations and Market Structure

\begin{tabular}{lll}
\hline Market Structure & Emission Tax & Tradable Permits \\
\hline $\begin{array}{l}\text { Perfect competition } \\
\begin{array}{l}\text { Noncompetitive market structure in } \\
\text { the output market }\end{array}\end{array}$ & $\begin{array}{l}\text { Efficient } \\
\text { Efficiency can be achieved by } \\
\text { suitably adjusting the Pigouvian } \\
\text { tax but only if firms are all } \\
\text { identical. }\end{array}$ & $\begin{array}{l}\text { Inefficient but literature suggests } \\
\text { that efficiency losses may be } \\
\text { smaller than under an emission tax } \\
\text { (when firms have different } \\
\text { pollution technologies). }\end{array}$ \\
& $\begin{array}{l}\text { Inefficient when firms have } \\
\text { different pollution technologies. }\end{array}$ & \\
$\begin{array}{l}\text { Noncompetitive market structure in } \\
\text { the permits market }\end{array}$ & n.a. & Inefficient \\
\hline
\end{tabular}

\section{Ease of monitoring/enforcement}

The third criterion refers to how difficult it is to make and interpret the necessary technical measurements to judge compliance with a reasonable degree of accuracy. In many cases, it is 
almost impossible — or at least extremely costly - to obtain accurate information about emission levels. But a central point is that the monitoring and measurement problems are no harder if an emission tax is involved than if compliance with a system of tradable permits is the concern. When permits are marketable, the problem may be compounded by the necessity of being current with completed trades. In other words, in this case, two types of monitoring are required: the monitoring of emissions as required under a emission tax as well as the monitoring of trades. This extra difficulty might be exploited by dischargers trading in the short run to stay one jump ahead of agency monitoring teams.

To lower excessive administrative and monitoring costs, regulators often target the polluting output and/or the inputs used in the production of polluting goods through the use of output and/or input taxes as alternatives for true emission taxes. ${ }^{8}$ Indeed, where emission taxes pose major problems for implementation, a tax levied at an earlier stage in the production cycle may be the preferable approach since monitoring of emissions levels is not required and it can be administered like any other tax, thereby reducing administrative costs (since governments do not need to create an additional administrative apparatus). While systems of this nature typically do not achieve the most efficient result economically, they are often preferred by policymakers who argue that the gains in terms of lower administrative costs exceed the efficiency losses. In contrast, targeting input or output rather than emissions is typically not applicable with a system of tradable permits, ${ }^{9}$ thereby reinforcing the relative appeal of the tax in terms of ease of monitoring and enforcement.

\section{Flexibility in the face of change}

For our purposes, flexibility is defined as the ease with which the system can be adjusted to maintain the desired ambient quality as the economy changes. The most common measures of ease are: (1) the amount of information the agency needs and the amount of calculations it has to do to produce the appropriate set of incentives for a new situation; and (2) the extent to which adjustments involve a return to a politically sensitive decision process. In terms of flexibility, it is often argued (see Bohm and Russell, 1985) that marketable permits have a distinct advantage over an emission tax. Once established, and assuming necessary monitoring and enforcement efforts, a permits system maintains either total emissions or ambient quality standards without constant intervention and recalculation by the regulator.

${ }^{8}$ This approach seems particularly warranted when inputs and/or outputs are assumed to be closely correlated with emissions.

${ }^{9}$ At a conceptual level, a system of marketable permits for input is conceivable (See Helfand, 1999). However, in practice such systems have never been used since it is extremely difficult to determine the levels of aggregate inputs use necessary to achieve a specified level of total emissions. Developing a system of marketable permits in input markets, then, will not clearly achieve a specified pollution level without a great deal of information on the part of the regulator. 
If the demand for permits shifts because of regional growth or decay, this will be reflected in the market prices of permits. Permits relocation takes place as long as firms find it in their interest to reduce emissions and sell permits to new entrants and/or expanding existing firms. In the case of an emission tax, the tax itself does not protect ambient quality unless it is adjusted by the regulator as change occurs. Such adjustment requires new calculation if the tax is to be efficient.

The above argument relies mainly on the fact that flexibility is defined from the perspective of the regulator. In the case of an emission tax, the adjustment responsibility to maintain a . fixed emission target in the face of change is borne entirely by the regulator. Hence, the adjustment process is typically associated with high administrative costs and, therefore, qualified as "less flexible." With a system of tradable permits, on the other hand, the adjustment responsibility in the face of change is borne by firms in the permits market. It is typically not associated with high administrative costs but it may be associated with high transactions costs. Indeed, trade of permits involves the costs of identifying exchange partners and revelation of willingness to pay and to accept. If these transactions costs are perceived to be high relative to anticipated gains from acquisition and/or sales of permits, there will be little exchange and the adjustment process may not take place. In such instances, the least cost configuration of emissions will not be achieved and a permits system may not be more flexible than an emission tax.

The efficiency and flexibility property of the permits system thus relies on the assumption that trading does indeed occur (e.g., transactions costs are low). How high are the transactions costs likely to be? Estimates of transactions costs for the United States EPA's Emissions Trading System were as high as 10-30 percent of the total costs (see Koustaal, 1997). Klaassen and Nentjes (1997) cite a figure of 5 percent for brokerage fee for the United States $\mathrm{SO}_{2}$ allowance trading program. The CFC and lead trading programs are also thought to have had relatively low transactions costs (Stavins, 1995 and Hahn and McGartland, 1989). Conversely, the Fox River biochemical oxygen demand (BOD) program appears to have been burdened by very high transactions costs, partly explaining the limited trading activity. Transactions costs are likely to be determined by the characteristics of the affected sectors. Koustaal (1997) argues that, in most cases, there is likely to be a positive relationship between the size of the market and transactions costs (i.e., the larger the market, the higher are the search and bargaining costs likely to be). In case of a thin permits market, the infrequency of transactions may not generate a clear price signal for firms to indicate the opportunity cost of their emissions and is likely to impair the functioning of the permits system, unlike a regime of emission taxes where the tax itself gives a clear and clean measure of the cost of emissions.

\section{Dynamic incentives}

The concept of dynamic incentives refer to the types of actions that are encouraged by the instrument in the longer run: does the instrument encourage entry or exit of firms (e.g., what is the impact of the instrument on industry size) and a search for and adoption of new, environment-saving technologies? 
Concerning the respective impact of the two instruments on industry size, both emission taxes and tradable permits raise emitters costs and thereby reduce their profits from the polluting activity. In the short run, firms may reduce output in response to the higher unit cost of production. In the longer term, if the industry producing the pollutant is competitive, some firms will leave the industry. As industry output falls, the price of the industry's product will rise, restoring normal levels of productivity for those firms, which remain. In the long run, both instruments result in reduced industry output and reduced pollutant emissions, compared to a situation of no pollution controls. It is important to note that whether tradable permits are auctioned or distributed freely makes no difference to industry output and emissions in the long run, provided that the initial distribution of permits is not conditional on whether the recipient continues to produce. If permits are issued "unconditionally," any amount paid to acquire a permit will, in effect, be a lump-sum payment to the initial recipient and will have no effect on firms' decisions to exit or enter the industry.

In practice, however, permits are rarely distributed unconditionally but rather in proportion to historical pollution, a system that is referred to in the literature as grandfathering. It has been argued (see Howe, 1994 and Stavins, 1998) that grandfathering creates a bias against new firms entering the product market since existing firms get their permits free while new firms must buy them. Hence tradable permits may foster noncompetitive market structure or higher industry concentration. Freely allocated tradable permits under a grandfathering scheme would convey rents to existing firms which would in effect be sustainable since, unlike auctioned permits or taxes, the freely allocated permits give rise to entry barriers. For this reason, auctioning of permits is typically preferred to grandfathering on economic ground.

Concerning the issue of providing incentives for technological change, if compliance is costly and if there is some choice of how to comply (e.g., what equipment or technique to use), then there will be an economic incentive for firms to seek cheaper ways of complying in the long run. In principle, the incentives for technical change provided by an emission tax are equivalent to those produced by a tradable permits system. In either case, reducing discharges produces a monetary gain to the firm. However, to the extent that the permits market is thin, the monetary gain may not materialize as easily under a permits system as under an emission tax. If firms do take such considerations into account, the incentive to switch to cleaner production techniques may be lower with a permits system. The literature also suggests that an auctioned tradable permits system is likely to have much stronger incentive effects than a system of grandfathered permits. This result is likely to arise for two reasons: (1) under an auctioned allocation, the innovating firm will get the benefit of lower permits prices if other firms adopt the innovation, while under a grandfathered scheme the decrease in price will benefit buyers, but hurt sellers (see Harrison, 1999); and (2) a system of grandfathering may prevent the entry of new firms on the market, and new firms are often important instigators of new production processes.

\section{Revenue-raising potential}

In terms of revenue-raising potential, the critical distinction is not much between an emission tax and a system of tradable permits per se but rather between systems where permits are 
freely allocated and systems where permits are auctioned. Both an emission tax and a system of auctioned permits generate government revenues. Yet, when evaluating these instruments as potential sources of government revenue, an apparent trade-off is highlighted between the primary function of these instruments (e.g., reducing pollution) and their revenue-raising function, an issue which will be taken up again below in the context of green tax reforms. Some authors (see Endres, 1997) have argued that environmental instruments cannot serve as the main pillars of public income since their primary purpose is to cut back the environmentally detrimental activity to which these activities apply. Hence, the tax is intended to erode its own base.

Oates (1992) argues that to implement an optimal tax, it is necessary to have a regulator whose interests transcend competing environmental and revenue pressures and who is in a position to weigh environmental concerns against revenue needs. This is a demanding institutional requirement, which is unlikely to be met in practice. Typically these instruments are introduced in either of two forms: by an agency concerned with environmental management, or by those whose primary responsibility is budgetary management and who are seeking additional sources of revenues. OECD (1996) argues that environmental taxes have typically been used as revenue-raising devices while tradable permits have been used primarily as instruments to reduce pollution. ${ }^{10}$

Emission taxes and tradable permits have mostly been examined in the literature as instruments for environmental management. Little has been said about the precise disposition of the revenues that these instruments may raise. There is one proposition that comes out of the standard environmental theory: the revenues should not be used to compensate the victims of pollution or for earmarking (see Baumol and Oates, 1988), as compensations may encourage a higher-than-optimal level of pollution.

In more recent years, the literature on environmental taxes has started to focus on the interaction between environmental taxes and the rest of the tax system. In this context, a critical question was raised, namely, is the welfare gain and hence the case for introducing environmental taxes greater or less than that implied by a partial equilibrium setting? It has been suggested that the welfare gains from an environmental tax are larger under a general equilibrium setting as the tax may simultaneously correct for the environmental externality and provide other gains, when the revenues are raised to cut other distortionary taxes (see Sandmo, 1975, and Parry, 1995 among others). However, more recent studies (Bovenberg and De Mooij, 1994, Goulder, 1995) have questioned the existence of this "double dividend." The double-dividend discussion has essentially centered on environmental taxes but could equally apply to a system of tradable permits to the extent that

${ }^{10}$ In most permit systems implemented to this date, permits were distributed free of charge and hence did not generate revenue for the government (this will be discussed in greater detail in the next section). 
the permits are auctioned (and hence constitute a source of public revenues). The issue of double dividend will be revisited in the next section when discussing green tax reforms.

\section{Political considerations}

Political considerations cover aspects such as distributional, ethical, and broader economic stabilization concerns, which may affect society's choice of policy instruments. We will limit our discussion to three issues that appear to be particularly important: distributional issues, competitiveness, and political acceptability.

Distribution. It is in principle possible to achieve the same distributional outcomes with an emission tax and a system of tradable permits. The emission tax embodies the polluter-pays principle, which involves the assumption that the recipients have the legal right to be free of emissions; thus polluters have to pay for the right to pollute. Government auction of marketable permits can achieve the same distributional results but clearly the equivalence would not hold when permits are allocated freely, because the permits in this case would represent a windfall gain for the (owners of the) receiving firms.

Distributional issues in the context of environmental taxes have centered on the potential regressivity of such type of taxes. The debate is more relevant in the case of product taxes (as opposed to emission taxes) since insofar as environmental taxes apply to mass consumption products, such as motor-driven vehicles and energy for instance, they may have a substantial effect on low-income households. OECD (1999c) argues that a distinction needs to be drawn between relatively low environmental taxes on products such as detergents, fertilizers, batteries, and pesticides, and large-scale and fiscally heavier taxes such as those on energy. In the first case, there seems to be no observable distributional impact, while in the second case, some studies indicate a risk of regressivity.

In the tradable permits literature, distributional issues seem to have received less attention. Nonetheless, such issues are relevant, especially in cases where permits are distributed freely, the key issue being the initial allocation of permits.

Competitiveness. Even if environmental policy considerably increases aggregate welfare, some economic sectors or regions may be adversely affected. In this respect, the impact of an emission tax and a system of tradable permits are likely to be equivalent provided that the permits are auctioned. If, on the contrary, the permits are freely allocated to firms, the equivalence breaks down (in such instances, the burden imposed on the firms is reduced and shifted to government in the form of reduced revenues).

For the firms directly affected by such systems (auctioned permits or emission tax), the issue of revenue recycling is key. In theory, it is possible that the existence of revenue recycling could entirely compensate firms for their cost, and thus there might be no reason to expect any competitiveness effect. Such schemes would clearly reduce the fear of any adverse competitiveness effect without granting existing firms the rent as under a grandfathered permits scheme. In practice, however, such revenue-recycling schemes are not used (most 
probably by fear that they would lead to a higher-than-optimal level of pollution in the long run). Hence in order to protect firm competitiveness, a grandfathered permits scheme would appear to be preferred (explicit effort can be taken to make sure that the rent is captured through proper taxes, profit tax, and the like).

The issue of competitiveness is also critical at the international level, focusing on the competitiveness of nations as opposed to firms. The key issue in this context relates to differences in environmental policies across countries that may affect competitiveness and trade patterns. The problems are particularly obvious when considering environmental taxes but the issue is also relevant (although somewhat different) with a system of tradable permits. Even under an international system of tradable permits, where several countries are regulated by the same central system, issues of competitiveness may arise. The critical issue is the initial allocation of permits, since whoever obtains the initial permit, especially if the permits are given out freely, will have a competitive advantage over whoever did not. The basic issues of the wealth effects of the international allocation of permits, and the absence of international institutions needed for cross-country enforcement are very complex and very different from those related to domestic use of tradable permits. The focus of this paper is on domestic tradable permits regimes. Overall, however, issues of international competitiveness have mainly centered around environmental taxes presumably because they make the costs of environmental protection more visible. ${ }^{11}$ This naturally leads us to the issue of political acceptability.

Political acceptability. From the firm's perspective, freely allocated permits are clearly preferred over an emission tax and/or auctioned permits because they convey rents to firms. Stavins (1998) also argues that tradable permits are preferred by environmental advocates who have a strong incentive to avoid policy instruments that make the cost of environmental protection highly visible to consumers and voters; and taxes make those costs more explicit than permits. Freely allocated permits are easier for legislators to supply than taxes or auctioned permits, again because the costs imposed on industry are less visible and less burdensome, since no money is exchanged at the time of the initial permits allocation. Joskow and Schmalensee (1998) argue that freely allocated permits offer a much greater degree of political control over the distributional effects of regulation, facilitating the formation of majority coalition. An auction, on the other hand, allows no such political maneuvering.

Obviously, the political considerations associated with the use of an emission tax and/or a system of tradable permits will also depend on how the revenues raised are spent. Overall, however, the critical distinction to evaluate the political impact of alternative instruments is not so much between an emission tax and a system of tradable permits per se, but rather

${ }^{11}$ As will be discussed in the next section, one of the main obstacles to implementing new environmental taxes is the possible loss of international competitiveness, as illustrated by the EU example. 
between systems where permits are freely allocated and systems where permits are auctioned. In many respects, the political considerations associated with a system of auctioned permits are very similar to that associated with an emission tax.

As Table 2 illustrates, from a theoretical perspective, no obvious result seems to emerge concerning which instrument (emission taxes or permits) is preferable to the other. This result stands in sharp contrast to the use that countries are actually making of the two instruments, as laid out in more detail in the following section.

\section{ENVIRonmental TaXes Versus Tradable Permits: ReVIEW of CoUnTRY EXPERIENCES}

This section addresses the issue of how - and to what extent-countries actually have made use of the two instruments of environmental control discussed above, and the practical administrative and technical problems encountered in this process. The review is meant to be illustrative rather than exhaustive, since keeping track of environmental policies in all countries would truly be an immense task.

\section{A. Broad Overview of OECD Experience with Environmental Taxes}

\section{Toward a definition of environmental taxes}

The theoretical literature on the choice of optimal instruments for environmental policy focuses for the most part on a pure emission tax. On the other hand, the practical reviews of country experiences seem to be using a much broader definition to capture the concept of an "environmental tax." Indeed, little consensus seems to exist in these reviews on the basic question of what constitutes an environmental tax, and different sources apply various definitions. In their overview of environmental taxes, McMorran and Nellor (1994) make a distinction between pure Pigouvian taxes, that is, taxes based truly on the units of emissions with specific rates set so that the net marginal benefits of reducing emissions by another unit would be zero; indirect environment taxes, that is, taxes on inputs or consumer goods whose use is related to environmental damage (e.g., excises on gasoline); and environment-related provisions in other taxes, including personal income taxes, corporate income taxes, general sales taxes, and fuels and motor vehicle taxes such as, for example, Germany's accelerated depreciation provisions for energy-saving and pollution-reducing equipment, and the lower VAT rates applied in a number of countries to pollution-reducing devices (e.g., recycled paper, solar energy equipment, etc.).

Box 2 reviews some other current definitions of an environmental tax. Obviously, the lack of a generally accepted definition has complicated the establishment of a consistent statistical 


\section{Table 2. Summary of the Basic Criteria for the Choice of Policy Instruments}

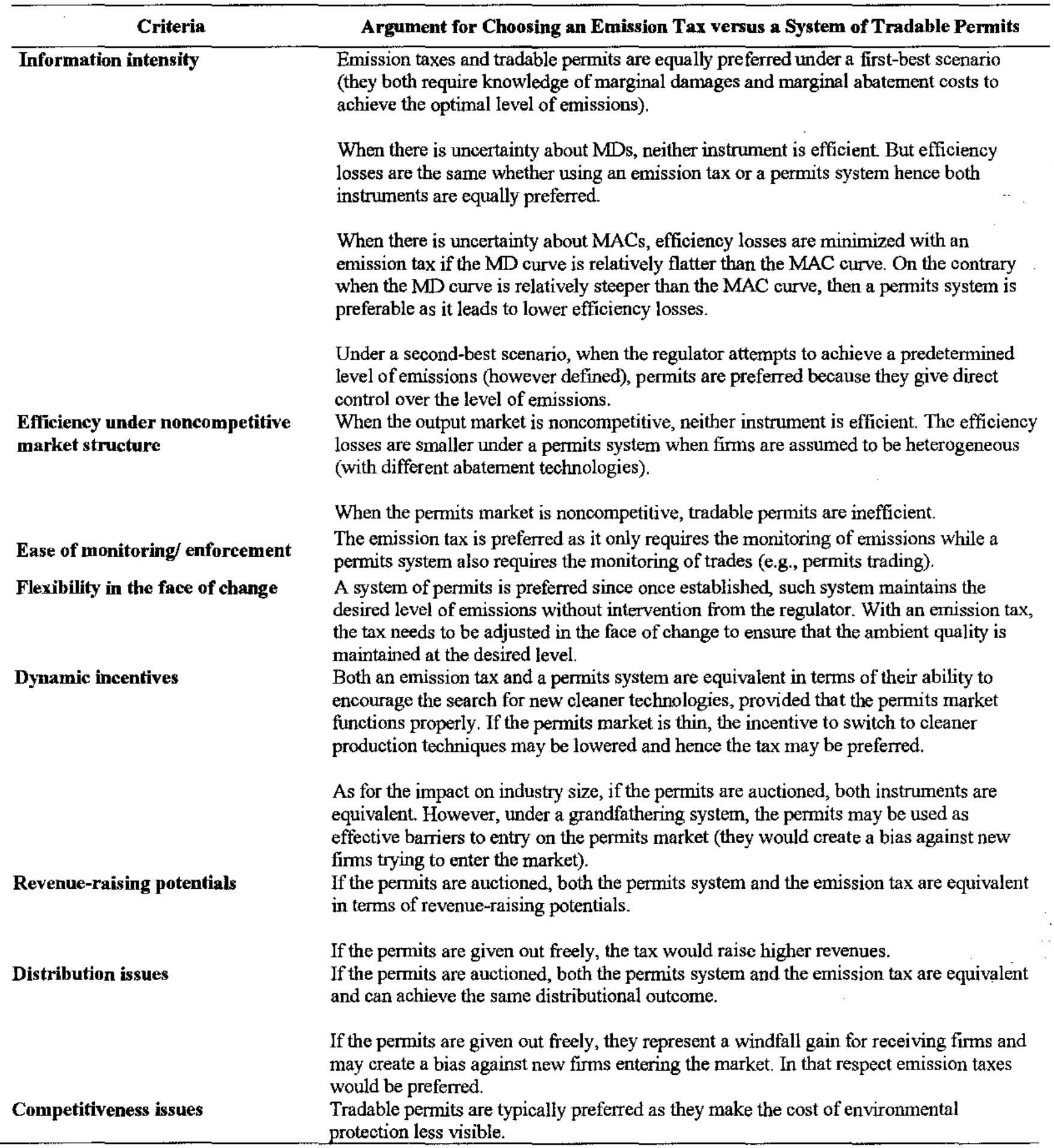




\section{Box 2. Defining Environmental Taxes, Charges, and Other Instruments}

EUROSTAT has used the following definition. A tax falls into the category of environmental if the tax base is a physical unit (or a proxy for it) of something that has a proven specific negative impact on the environment, when used or released (OECD, 1997b).

$\mathrm{OECD}, 1999 \mathrm{c}$ defines environmentally related taxes as any compulsory, unrequited payment to general government levied on tax bases deemed to be of particular environmental relevance. This definition would exclude all environmentally related fees and charges that are requited payments to government. Also, according to this definition, the name or the expressed purpose of the tax is not a relevant criterion. However, in that same publication (and on the face of it not fully consistent with the above definition), an important aspect is noted to be "the potential environmental effects of the given tax, which is determined by the tax impacts on the producer and consumer prices in question, in conjunction with the relevant price elasticities."

$\mathrm{OECD}, 1996$ offers the following more elaborate definitions:

Emission toxes involve tax payments that are directly related to the measurement (or estimation) of the pollution caused, whether emitted into air, water, or soil, or due to the generation of noise. Emission taxes generally deal with one type of emissions at a time. They are directed to the last link in the chain, that is, to those actually emitting a certain substance into the environment, and are usually only suitable for stationary sources because of their high monitoring and administrative costs.

Product charges or taxes can be a substitute for emission taxes when direct measurement of emissions is not possible. More generally, product taxes may be levied to price environmental effects correctly, and could be used to correct externalities other than pollution. A product tax may be levied on the units of harmful substance contained in products: for instance, a carbon tax is based on the carbon content of each particular fossil fuel. The product tax may also be levied per unit of the product, if the objective is to reduce usage of the product generally. Product charges may be applied to raw materials, intermediate, or final (consumer) products. When applied to consumer products, they are often called consumption taxes or final-product taxes. Consumption taxes may be used when pollution is closely linked to consumer demand, such as disposable products that compete with reusable alternatives, or nonfuel efficient cars. In this case, the taxation may be linked to the product itself or parts of its contents that are detrimental to the environment. When applied to raw material (e.g., coal to produce electricity) or intermediate products (e.g., polyvinylchloride to produce plastic), product taxes are referred to as input taxes. Emission taxes on production activities and input taxes are referred to as production taxes.

Tax differentiation relates to variations in existing indirect taxes, such as excise duties, sales taxes, or valueadded taxes for environmental ends. Goods and services that are associated with environmental damage in production and consumption may be taxed more heavily (e.g., most OECD countries apply different excise tax rates to leaded and unleaded petrol).

User charges are payments related to the service delivered. Only those connected to the relevant service are charged. The revenues raised are used to provide a service, such as the collection and public treatments of effluents. They are considered environmental tax instruments because the service they fund seeks to improve the quality of the environment and to reduce the use of natural resources such as water and land. Given their cost recovery nature, user charges are a direct application of the polluter-pays-principle.

Tax reliefs consist of various provisions in income tax systems designed to encourage some kind of behavior, either by consumers or businesses. The most common form of tax relief is accelerated depreciation, but many countries also provide investment tax credits for certain types of investment, such as pollution control equipment, or for research and development. 
classification of such taxes. ${ }^{12}$ Depending on the nature and scope of the definition chosen, the concept of environmental or ecotaxes may encompass only pure emission taxes, or these as well as product taxes, which may be only indirectly related to actual emissions. In practice, and using the wider definition preferred by the $\mathrm{OECD}$, most environmental taxes are not true emission taxes, ${ }^{13}$ but take the form of product taxes.

For the purposes of this paper, the approach adopted focuses to the extent possible on pure emission taxes, that is, the discussion generally excludes product taxes on energy (although some revenue data are provided on the wider concept applied by the OECD).

\section{The nature and revenue importance of environmentally related taxes in the OECD}

Following the OECD's broad definition of the concept (i.e., including all environmentally related product taxes, and in particular taxes on petroleum products, see OECD, 1999a). Figure 4 shows, for the 19 countries covered by the OECD databank, that the (weighted) average of the ratios of ecotaxes to GDP is just below 2 percent, with the highest ratio in Denmark (well above 4 percent) and a ratio close to 4 percent in the Netherlands, Norway, and Portugal. The lowest ratios (around 1 percent) are found in Mexico and the United States. A similar wide dispersion among the countries in this sample is found with respect to the weight of ecotaxes in total taxes, around an average of about $5 \frac{1}{2}$ percent.

Figure 5 shows estimates of the corresponding revenue raised from the individual tax bases for the group of countries as a whole. Evidently, by far the largest individual revenue raiser is unleaded petrol with almost 40 percent of the revenue raised (in 1995), followed by more than 20 percent raised from taxes on the use of motor vehicles. It is interesting to note that the taxes on petrol and diesel together with the taxes on the sale or use of motor vehicles generated more than 91 percent of all the environmentally related tax revenue covered by the OECD study. In other words, in relative terms, the revenue raised from pure emission taxes is very modest. However, while this holds for the OECD countries as a group, in individual countries, and in particular in the "ecotax leaders" dealt with below, emission taxes may be of quite some revenue importance. Despite these broad developments, there has been no strong general move toward comprehensive green tax reforms, except in a limited number of countries.

${ }^{12}$ To address this problem, the OECD in cooperation with other institutions is working on a statistical framework, which in time will provide a clearer picture of the level and structure of environmental taxation in developed countries. In the same context, the OECD has also established a comprehensive database with information on environmentally related taxes in its member countries (OECD, 1999a).

${ }^{13}$ In practice, the concept of a true Pigouvian tax set optimally such that it equals the marginal damages of emissions is rarely applicable, given that regulators are unlikely to have the information needed to set such a tax (see Section II). 
Figure 4. Revenues from Environmentally Related Taxes in Percent of Total Tax Revenue and GDP, 1995

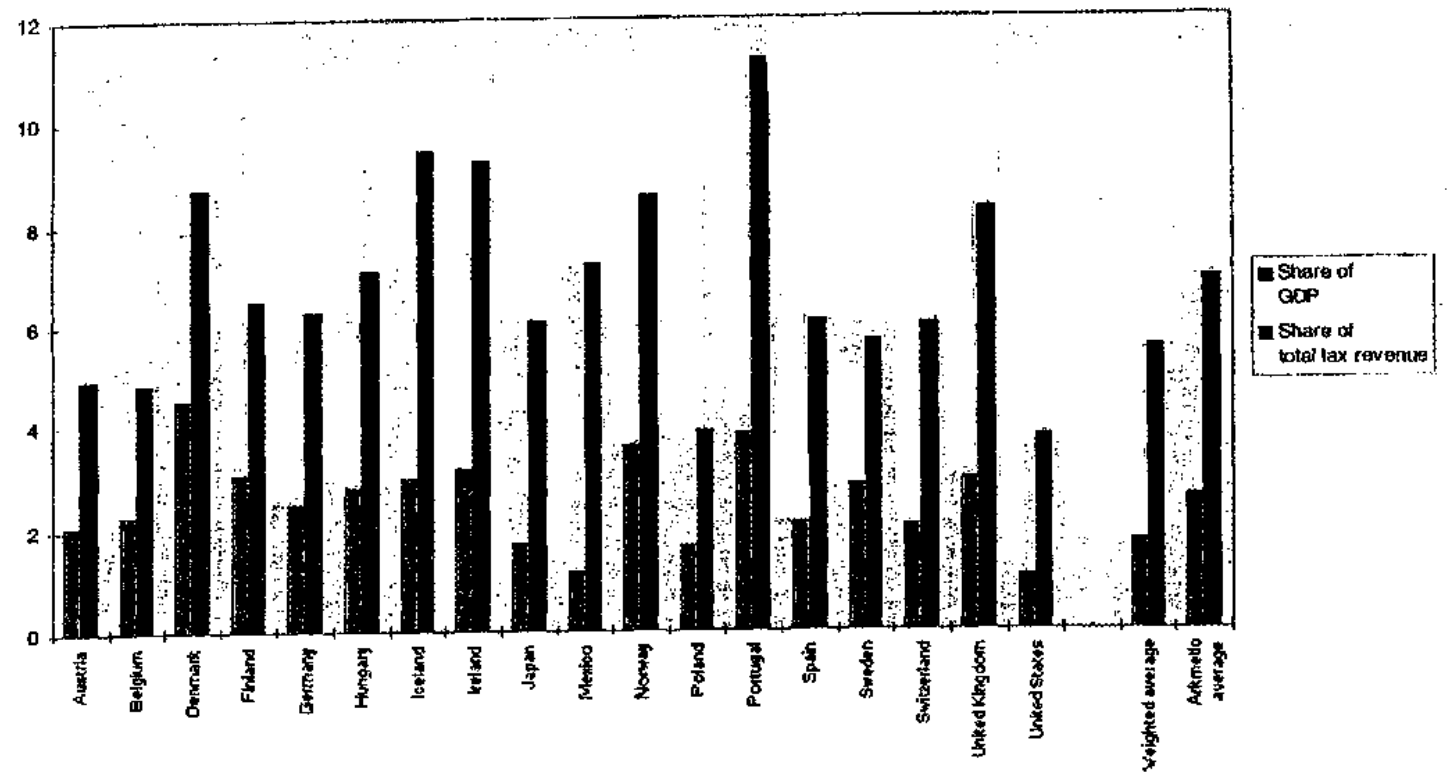

Source: OECD (1999c).

Figure 5. Revenues from Environmentally Related Taxes in 1995

(In millions of U.S. dollars)

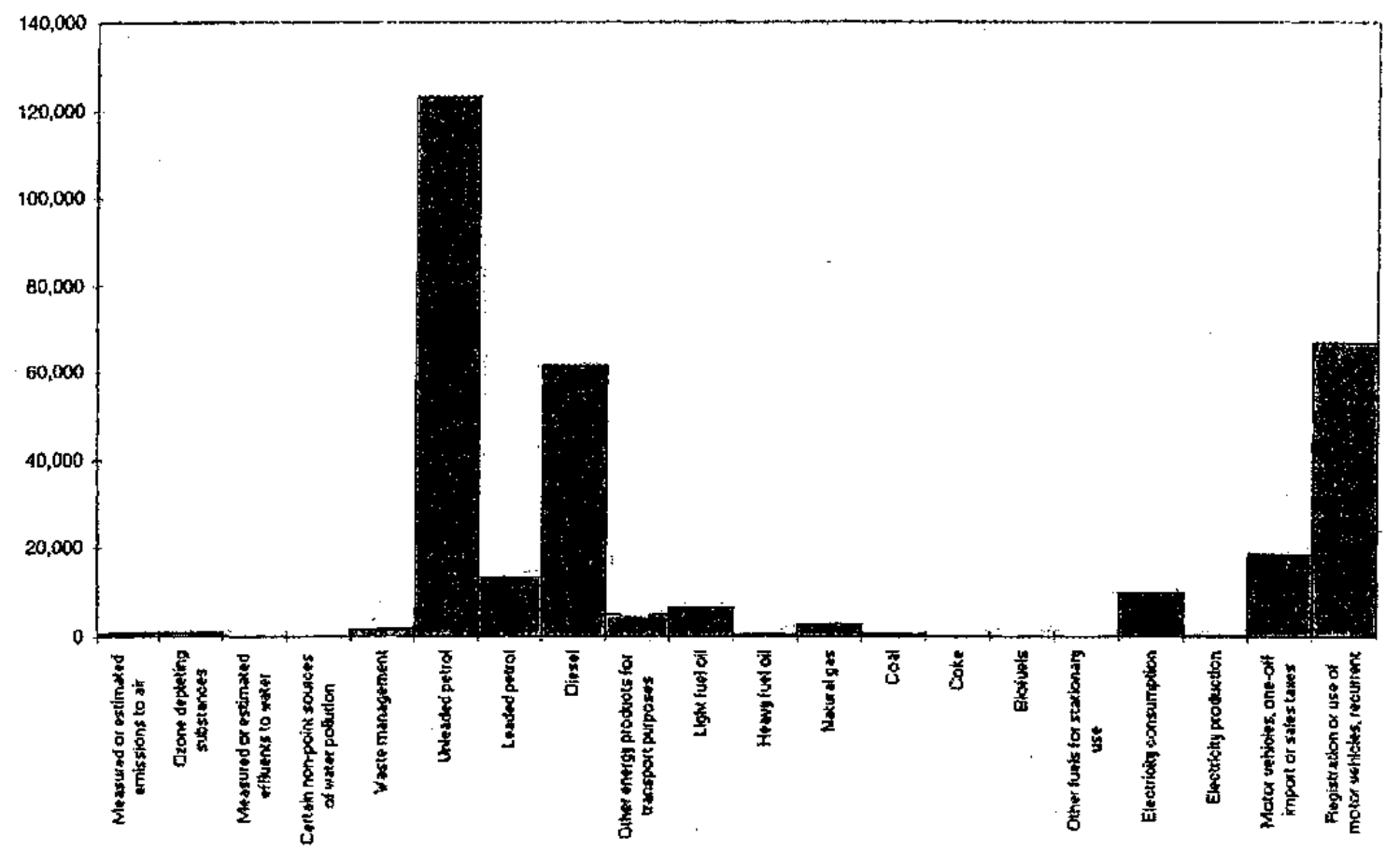

Source: OECD (1999c). 
Overall, a distinction can be made between two groups of (developed) reform countries: the first encompasses countries which have opted for a radical restructuring of the overall tax system, with increased reliance on environmental taxes, and includes Denmark, Norway, Sweden, and the Netherlands. The other group of countries is characterized by important but more incremental policies in this area, and encompasses Austria, Finland, Germany, Belgium, France, and Switzerland. The distinction, though, is to some extent subjective. The focus of this section is on the former group referred to as the "ecotax leaders." This focus was adopted mainly for two reasons: first, comprehensive overviews of the use of environmental taxes and tax provisions have been attempted elsewhere (see, in particular, OECD 1995, 1997b, 1999b, and McMorran and Nellor, 1994); and, second, the experiences of the "leaders" may well provide some useful lessons for other countries with respect to which taxes realistically can be applied; the administrative and other complications they may meet in trying to do so; and the revenue yields that can realistically be expected.

\section{Trends in and objectives of the reforms of the "ecotax leaders"}

Generally, reforms of environmental taxes may be based on three different approaches or combinations thereof (OECD, 1997b): (1) a removal or modification of existing distortionary subsidies and tax provisions; (2) a restructuring of existing taxes to take account of environmental considerations; or (3) the introduction of new ecotaxes. Characteristically, in the countries having implemented comprehensive "green tax" reforms, all three approaches have been attempted. Also a key characteristic is the fact that environmental tax reform in these countries have been implemented as part of fundamental tax reforms with a much wider scope than just that of improving the environment.

Appendix I provides summaries of the main environmental tax provisions introduced in Denmark, Norway, Sweden, and the Netherlands. The recent experiences of green tax reforms in these countries illustrate the variations both in the approach and scope of the reforms, as well as in the implementation strategies chosen across countries. But, perhaps more importantly, they also show some important general issues and problems which have confronted the early reformers. These experiences may be useful for other countries in their preparations for green tax reform. In our view the following six issues, some of which have been touched upon in the conceptual discussion above, figure prominently in this context.

First, the reforms have not taken place in a vacuum but have been adopted against a common background of international agreements to reduce emissions of greenhouse gases. This background follows in turn from the increasing scientific consensus that global warming is underway and is linked in part to the emissions of greenhouse gases. In some countries such as Norway, the goal of taking the lead internationally has, indeed, played an important role in the domestic reform debate. The OECD and European Union constitute important focal 
points for discussions and exchange of information on these issues among developed countries, and have taken innovative initiatives in this respect. ${ }^{14}$

The most prominent international agreement is the Kyoto Protocol, agreed in 1997 but yet to enter into force, ${ }^{15}$ which calls for a reduction of greenhouse gas emissions of some 7 percent on average for OECD countries in 2008-2012 relative to their base level (generally 1990). ${ }^{16}$ Because of significant increases in emissions since 1990, the "effective" reductions implied by the Protocol are typically significantly larger than the 7 percent mentioned above for OECD countries as a whole (under a "business as usual" scenario, required reductions are . about 30 percent). The European Union has adopted a separate burden-sharing agreement to achieve the targets under the Protocol for its 15 membership countries. While few of the specific domestic policies necessary to achieve the targets are in place today, much research has gone into estimating the costs of implementing the Kyoto targets. Simulations seem to suggest that if the targets are met using only cost-effective domestic measures (i.e., disregarding mechanisms such as international emission trading), real income in the OECD overall would be reduced by about $1 / 2$ percent-seemingly a modest reduction, but hiding much larger impacts on some sectors. Moreover, the estimates are based on some strong assumptions, and may well underestimate the true costs (see OECD, 1999b). ${ }^{17}$ International trading of emission allowances could substantially lower the costs and would generally allow OECD countries to meet the targets with higher levels of GDP, but as with other parts of the implementation, little progress has been made with regard to the practicalities of international emission trading.

Second is the fact that the introduction of $\mathrm{CO}_{2}$ taxes have been the common key element of all the reforms discussed here. Hence, all the countries have found that the most efficient way to achieve environmental objectives is through emission taxes targeting $\mathrm{CO}_{2}$ emissions, which are by far the dominant green house gas. However, since technical complexities

\footnotetext{
${ }^{14}$ In September 1999, for example, the Environment Committee of the European Parliament passed a draft resolution on climate change containing a harmonized ecotax plan in which the $15 \mathrm{EU}$ countries can opt in or out.
}

${ }^{15}$ The Protocol will not enter into force until ratified by countries accounting for at least 55 percent of so-called Annex 1 emissions, and by at least 55 countries. Eight countries have ratified so far, but none of the Annex 1 countries. The institutions and procedures for monitoring and reporting of noncompliance are yet to be established.

${ }^{16}$ Developing countries are not subjected to binding targets under the Protocol, and only a few of these countries have voluntarily adopted emission targets similar to those of the developed countries.

${ }^{17}$ The costs are also estimated to increase over time, and will reach $1 \frac{1 / 2}{2}$ percent of GDP in 2050 if emissions are to be maintained at the level embodied in the Protocol. 
prevent fully accurate measurements of actual emissions, the tax bases are measured as the estimated average carbon content of the products in question; hence, in practice, these taxes fall somewhere in-between product taxes and pure emission taxes (see Box 2). Also, as illustrated in Table 3 , the rates of the tax chosen vary markedly across countries (for convenience, the rates are shown in Norwegian Kroner). Norway and Sweden have introduced by far the highest tax rates, although it should be noted that statutory rates may be somewhat misleading indicators of the "effective" rates owing to differences in the scope of exemptions granted across countries. ${ }^{18}$

Table 3. $\mathrm{CO}_{2}$ Taxes in Selected Countries (Norwegian kroner per ton $\mathrm{CO}_{2}$ )

\begin{tabular}{|c|c|}
\hline & NOK per ton $\mathrm{CO}_{2}$ \\
\hline \multicolumn{2}{|l|}{ Norway (1997) } \\
\hline Gasoline & 376 \\
\hline Natural gas & 373 \\
\hline Oil & 328 \\
\hline Light mineral oil & 164 \\
\hline Heavy mineral oil & 140 \\
\hline Coal & 179 \\
\hline Coal & 136 \\
\hline \multicolumn{2}{|l|}{ Sweden (1996) } \\
\hline Gasoline & 354 \\
\hline Auto diesel & 380 \\
\hline Natural gas & 321 \\
\hline LPG & 352 \\
\hline Light mineral oil & 380 \\
\hline Heavy mineral oil & 326 \\
\hline Coal & 362 \\
\hline \multicolumn{2}{|l|}{ Denmark (1996) } \\
\hline $\mathrm{CO}_{2}$ households & 111 \\
\hline $\mathrm{CO}_{2}$ industry & 56 \\
\hline \multicolumn{2}{|l|}{ Finland (1996) } \\
\hline $\mathrm{CO}_{2}$ & 53 \\
\hline \multicolumn{2}{|l|}{ The Netherlands (1994) } \\
\hline $\mathrm{CO}_{2}$ & 20 \\
\hline
\end{tabular}

Source: Thorvald Moe (1999; Table 8.1)

18 "Effective" rates of taxation could be measured as the ratio between actual green tax yield collected and the potential tax base (that is, including what is currently exempt). Data deficiencies have prevented the calculation of effective rates. 
Third, the green tax reforms dealt with here have generally not intended, as their main motivation, to raise significant amounts of revenue; indeed, in most cases, a dual objective have been pursued by applying measures aimed at improving environmental conditions, mainly through increased taxation, and at the same time to utilize the resources raised to alleviate the distortions created by other taxes, first of all taxes on labor. In Denmark, this was done through reductions in the marginal tax rates on labor income and reduced social security contributions; in Sweden, a major general reduction in income taxation was implemented; and in the United Kingdom, the Climate Change Levy announced by the chancellor in March 1999 is intended to be balanced by a reduction in National Insurance contributions. While employment considerations have played an important role in the reform initiatives, it should be recalled, though, that the employment impact generally is expected to be fairly modest (see Appendix I for country examples); but also that the primary raison d'être of any green tax reform is relative price corrections and not its revenue-raising capabilities. More generally, many of the reforms reflect the strive toward less distortive tax systems that at least could alleviate some tax-induced distortions with an adverse impact on employment and at the same time would remove incentives to degrade the environment.

Fourth, and closely related to the issue of revenue neutrality, is the alleged adverse impact that the introduction of green taxes may have on international competitiveness. As noted in Appendix I, this issue has so far barred progress on a harmonized green tax reform in the EU. Industry arguments about adverse effects on competitiveness have led countries to grant tax exemptions mainly to heavy emitters, even though these exemptions tend to seriously weaken the link between the tax paid and carbon emitted and, obviously, reduce the yield from the tax and hence the potential for reducing labor taxes. To mention just a few examples, these considerations have played a significant role in the discussions: in Germany, where the energy tax is capped; in Finland, where the electricity sector has been exempted from the carbon tax; in Denmark, where the yield from emission taxes are "recycled" to industry, and taxation in some cases have been replaced by voluntary agreements; and in Norway, where possible steps to scale back the carbon tax to counter a fall in investment in the oil sector, prior to new offers for oil exploration, are being contemplated. Hence, key policy interactions between environmental goals and considerations of competitiveness and regional development have played and still play a dominant role in the scope and practical design of environmental taxes at both the national and international level. The ongoing discussions in the United Kingdom on the introduction of the Climate Change Levy provides another clear example of the inherent political and economic controversies involved in basic green tax reforms.

Fifth, perhaps of less political significance than the competitiveness issue, is the perception that green taxes are predominantly regressive, as supported by a number of empirical analyses. However, at their present levels, ecotaxes do not seem to have any significant regressive impact, although some simulation models involving significant carbon taxes indicate modest regressivity (OECD, 1997b), Section II; see also Appendix I, Section III on Sweden). It should be noted, though, that-ideally-the distributional consequences of ecotaxes should be measured net both in relation to the taxes that they replace in cases of revenue neutral reforms (mainly labor taxes which may be heavily regressive) but also with 
regard to the incidence of the environmental improvements that they generate, which may well be progressive.

Sixth and lastly, the sustainability of ecotax revenue has been noted as an important issue because of the trade-off between the environmental and the fiscal (revenue-raising) objectives of ecotaxes: there are merits to the view that ecotaxes should be analyzed using the same basic criteria typically applied to taxation in general: efficiency, equity, simplicity, and buoyancy. However, for a typical ecotax, there may well be trade-offs which are lacking for other type of taxes since, in a sense, pure Pigouvian ecotaxes are ultimately aimed at eradicating or certainly limiting their own bases, that is, there is a conflict between the economic efficiency and buoyancy objectives. Thus, while fiscal considerations would favor a broad and stable revenue basis, from an environmental point of view the aim of an ecotax is to diminish its own base. Perhaps the most successful example in this context is the impact of high excises on leaded petrol (as compared to those on unleaded petrol) in many OECD countries which may help to explain the total disappearance from the market of this product in some countries (Austria, Denmark, Finland, Norway, and Sweden). However, as this example illustrates, ecotaxes may change the composition of consumption (in this case petrol) through substitution from highly polluting to more cleaner products, but still with a substantial and fairly stable (price inelastic) tax base intact (in this case in the form of unleaded petrol).

More generally, the conflict between fiscal and environmental objectives should not be overstated. For instance, the base of many existing $\mathrm{CO}_{2}$ taxes seems to be fairly stable or even growing in countries where such taxes have been introduced, and at their present levels, existing environmental taxes are not likely to trigger strong behavioral changes or demand shifts. Furthermore, there still seems to be ample opportunities for introducing or increasing taxes on harmful or polluting products, which have a fairly low demand elasticity. This may, however, change in the future with increased use of these taxes and as indicated earlier cases have, indeed, occurred where a tax has had a substantial impact on its own base, the Swedish sulfur tax being one good example.

\section{B. Limited Experience with Tradable Permits}

Tradable permits systems are implemented only in a few countries, and with limited scope. One notable exception is the case of the United States where support for the use of this market approach has clearly grown, as reflected by the increasing number of applications both by the federal government and by state governments. Appendix II reviews the United States experience and briefly discusses the limited use of tradable permits schemes in other countries, both developed and developing.

The United States was the first country to apply tradable permits widely in the context of its environmental protection programs, and even today, most applications of tradable permits can be found in that country. These applications have mainly related to the emission of air pollutants, but both water-based and land-based applications have also been used at times. There have also been applications in other OECD countries (e.g., Germany, Australia), but 
usage of the instrument has been much less in these countries than in the United States. Table 4 provides an overview of the main tradable permits systems currently in place in OECD countries. Specific country experiences are discussed at length in Appendix II.

Table 4. Summary of Main Tradable Permits Applications in OECD Countries

\begin{tabular}{|c|c|c|c|c|c|}
\hline Country & Program & Period & Type of Program & Initial Allocation & Banking \\
\hline \multicolumn{6}{|l|}{ Air protection } \\
\hline United States & EPA Emission Trading Program & $1975-$ & Credit-Based & n.a. & Yes \\
\hline United States & EPA Lead-in Gasoline Program & $1982-87$ & Cap-and-Trade & Grandfathered & Yes \\
\hline United States & Post-Montreal CFC Trading System & 1988- & Cap-and-Trade & Grandfathered & No \\
\hline United States & $\mathrm{SO}_{2}$ Allowance Program & $1990-$ & Cap-and-Trade & $\begin{array}{l}\text { Grandfathered } \\
\text { (auctioned) }\end{array}$ & Yes \\
\hline United States & RECLAIM & $1992-$ & Cap-and-Trade & Grandfathered & No \\
\hline United States & OTC Nox Budget & $1994-2003$ & Cap-and-Trade & Grandfathered & Yes \\
\hline Germany & VOC Control & 1993- & Credit-Based & n.a. & Yes \\
\hline \multicolumn{6}{|c|}{ Water protection } \\
\hline U.S./Wisconsin & Fox River & 1981- & Credit-Based & n.a. & No \\
\hline U.S./Colorado & Dillon Reservoir & 1984- & Cap-and-Trade & Grandfathered & No \\
\hline Australia & Murray-Darlin Basin Program & $1988-$ & Cap-and-Trade & Grandfathered & Yes \\
\hline \multicolumn{6}{|l|}{ Fisheries } \\
\hline Australia & Individual Transferable Quota (ITQ) & & Cap-and-Trade & Grandfathered & No \\
\hline Canada & ITQ & & Cap-and-Trade & Grandfathered & No \\
\hline Iceland & ITQ & & Cap-and-Trade & Grandfathered & Yes \\
\hline Netherlands & ITQ & & Cap-and-Trade & Grandfathered & No \\
\hline New Zealand & ITQ & & Cap-and-Trade & Grandfathered & No \\
\hline United States & ITQ & & Cap-and-Trade & Grandfathered & No \\
\hline
\end{tabular}

Source: OECD (1999d).

While the theoretical advantages and characteristics of tradable permits have been well established for many years in the literature (see Section II), there are many decisions that must be made to turn theory into practice. We first present some of the issues that may arise in a practical setting but are typically not discussed in most studies. Harrison (1999) suggests organizing these decisions into three broad categories (i.e., threshold, design, and implementation issues), corresponding roughly to the chronology in which they would be addressed. 
Threshold issues include decisions regarding the basic purpose and nature of the system, most specifically with respect to: (1) the emission goal to be achieved--this includes the distinction of whether the system is set up when emission goals are set, or whether the system is set up as an adjunct to existing goal; (2) geographic area covered - this includes the decision of whether trade can be made within local air quality control regions, states, or group of states; and (3) the nature of the commodity to be traded-these issues include the important distinction between two types of programs: cap-and-trade versus credit-based systems. In the former, overall emissions are capped and parties trade an allowance (i.e., the right to emit a unit of the given pollutant). In the latter, the commodity is an emission reduction credit (i.e., a credit based upon the showing that the seller has reduced emissions below a baseline level).

Design issues cover issues such as: (1) the allocation of initial allowances (note that this issue is only relevant in a cap-and-trade program); (2) geographic or temporal flexibility or restrictions--this includes the possibility of restricting trade among different parts of the geographic range of the program, and the possibility of banking (i.e., reducing emissions more than is required and "banking" the surplus for future internal use or sale);

(3) specification of emission sources that are required or allowed to participate-this includes the possibility of allowing other sources to "opt in" to the program; and (4) possible establishment of institutions to facilitate trading.

Implementation issues cover issues such as (1) the certification of permits-whether emission restrictions must be certified before they can be traded; (2) the choice of methods for monitoring and reporting emissions; and (3) the means of determining compliance and enforcing.

\section{Lessons learned from the United States experience}

We suggest a number of important lessons that might be drawn from the United States experience. $^{19}$

First, tradable permits remain somewhat controversial, even in the United States with its relatively long history with the instrument. Overall, and at least in the case of permits systems aimed at air pollution abatement objectives, political support for these systems seems highest when they are introduced as completely new initiatives, rather than add-ons to already existing program. There are several potential explanations for this (see Stavins, 1998), the main one being the lack of constituencies for the status quo, namely new programs do not have the difficulties of modifying expectations that are set up for existing programs among various constituencies.

${ }^{19}$ These lessons are drawn for the most part from the proceedings of an OECD workshop held in Paris in September 1998, on the theme: "Domestic Tradable Permit Systems for Environmental Protection: Issues and Challenges." 
Second, tradable permits programs can be implemented at different geographic scales. Successful tradable permits systems have been established for sources throughout the United States (e.g., $\mathrm{SO}_{2}$ trading program, lead-in gasoline), as well as for sources in individual geographic areas (e.g., California's RECLAIM). In both cases, however, trades take place in a single administrative region. No existing program so far has involved trades across different states or different air quality control regions within a state. The $\mathrm{NO}_{\mathrm{x}}$ Budget Program represents the first attempt at such program and should provide important information on the additional issues involved in interstate programs. There appears to be a trade-off between the increased efficiency generated by expanding the size of the permits market, and the risk of creating environmental "hot spots" ${ }^{20}$ as a result of increased trading. In some programs, this problem has been solved by constraining the size of the market, so that only nearby emitters can trade with each other. Another approach is to use two types of environmental regulations. For instance in the $\mathrm{SO}_{2}$ program, there are no geographical constraints on the market (i.e., trading can occur between any two participating firms); however, these firms are also subject to additional local environmental constraints.

Third, cap-and-trade programs are used more frequently than credit-based programs. Overall, the volume of trading in these programs tend to be larger than it is for emission reduction credit systems. This is at least partially because the commodity being traded is usually better defined, therefore reducing the obstacles to trading and increasing the likelihood of potential costs savings. Credit-based trading requires the computation of arbitrary and often controversial baselines in order to establish a reference point for future reductions, often ending up with permanent administrative oversight and/or cumbersome certification procedures. This uncertainty may also complicate the initial allocation of rights, which can involve controversial procedures and assessments.

Fourth, determining the initial allocation of permits is crucial. Despite a theoretical preference for an auction approach, grandfathering of the initial permits has been applied in virtually all applications that have been observed in practice. Only in the $\mathrm{SO}_{2}$ allowance program is a portion of the permits offered at auction. This is done in an attempt to make up for market imperfections and/or to accommodate newcomers to the market. Usually grandfathering is done to achieve some perceived equity considerations. As long as the number of firms, which are granted permits free of charge is large, and as long as the systems eliminate rents from the newly created assets, grandfathering seems to be socially acceptable. However, there was a least one case where the boundaries of social acceptability were apparently surpassed. This involved ozone depleting substance quotas allocated in the United States under the Montreal Protocol. In this case, CFC producers and importers were expected to receive large windfalls gains as a result of the introduction of the system. These windfalls profit were then taxed away by the United States Congress.

${ }^{20}$ Hot spots are very high concentrations of pollution in particular locations; tradable permits could contribute to the formation of such hot spots if they allowed more clustering of emissions in vulnerable areas. 
Fifth, allowing intertemporal trading (banking) can provide important flexibility for sources to undertake early reductions in order to accumulate allowances that can be used to ease compliance in the future. Most tradable permits systems in the United States have used banking. This flexibility appears particularly important when reductions are phased in over time such as in the $\mathrm{SO}_{2}$ allowance program and lead-in-gasoline program. By allowing early abatement efforts to be banked for later use, the environmental benefits can be increased, in the sense that large emission reductions are achieved when emissions are the highest (i.e., when the marginal damages from emissions are the highest). There are also economic benefits associated with banking because it reduces the exposure of emitters to a large shift in permits prices.

Sixth, private institutions typically develop to facilitate trades and provide market information, although government institutions (e.g., auctions) can be useful initially. Brokers are important elements of the trading program for both the $\mathrm{SO}_{2}$ allowance program and RECLAIM. The brokers lower the overall transactions costs for trades, increasing the volume of trades and overall costs savings. In the $\mathrm{SO}_{2}$ program, for instance, brokers and other private market transactions account for the bulk of allowance sales and purchases. In contrast, few transactions are accounted for by the auction mechanism set up to help newcomers. Such auctions can, however, be useful in the early stage of the program to provide information on prices.

Seventh, flexibility in monitoring requirements may increase participants beyond large sources. Emissions under a cap-and-trade programs must be monitored to ensure that the quantity of allowances purchased and sold is accurate. Continuous emission monitoring systems offer some degree of certainty in the emission monitoring process, and are therefore often mandated by tradable permits programs. However, this costly requirement often precludes the participation of small emitters (such as in the case of the $\mathrm{SO}_{2}$ program for example). ${ }^{21}$ Experience with the RECLAIM program on the other hand proves that it is possible to combine both large and small sources, with different regimes being applied to both groups. In that case, small firms were given an opportunity to participate in the program, with emissions being estimated (e.g., by fuel meters and/or using emission technology factors). However, it should be noted that this approach has only been tried in the United States, where emitters tend to be covered by a complex and well-established system of supplementary environmental controls, in addition to the permits system itself. Similar programs replicated in other jurisdictions may face compliance and enforcement problems.

\section{The Scope for Taxes and Tradable Permits: Tentative Conclusions}

This paper has presented the relative merits of green taxes vis-à-vis tradable permits as the two dominant economic instruments in pollution control. From a conceptual and theoretical

${ }^{21}$ In some instances, the combined emissions from small emitters may turn out to be more significant than those of the larger emitters. 
point of view, the two instruments have many similarities and no obvious result seems to emerge concerning which instrument is preferable to the other. From a practical point of view, however, there is no doubt that the majority of countries engaging in the use of economic instruments for environmental policy purposes have relied much more on taxes than on tradable permits. The reason is presumably that taxes constitute a more familiar tool than permits - a tool that, furthermore, can be implemented through an existing administrative apparatus. Tradable permits, in contrast, are new policy instruments, which have a lot of promise, but with which governments and their administrations are less familiar.

Given the positive results achieved so far in various programs in the United States, tradable permits systems seem likely to continue to be applied in the United States (and perhaps even at an increasing rate). However, the political climate for tradable permits in Europe is not as certain and several European governments are currently contemplating or engaging in longterm programs involving mainly environmental taxes. For those countries, we suggest three important lessons, based on the experience of the ecotax leaders:

- $\quad$ First, green tax reforms should not be expected to yield significant revenue. Consequently, realistic expectations must be adopted concerning the existence of a double dividend, including the potential for a significant positive impact on employment. True ecotaxes are more likely to be successful as environmental instruments rather than fiscal instruments.

- Second, $\mathrm{CO}_{2}$ taxes have been at the core of all the reforms discussed. Hence, all countries concerned have found that the most efficient way to achieve environmental objectives is through emission taxes targeting $\mathrm{CO}_{2}$ emissions, which are by far the dominant green house gas.

- Third, there is an important trade-off between environmental objectives and the potential loss of international competitiveness relative to other countries that impose lower or no such measures. Considerable opposition should be expected as a result of the imposition of MBIs, particularly from the industries most affected by the introduction of such systems. This calls for careful design of the "recycling" mechanisms to be adopted for revenues, along with careful consideration of phasingin provisions and extensive consultation and information campaigns prior to the introduction of any such reform.

As for tradable permits, both actual experiences (in the United States mainly) and willingness to experiment with it seem to be expanding. Experiences gained at the national level may, furthermore, help to ensure wider implementation at the international level-an important consideration in view of the fact that trading forms a key part of the Kyoto Protocol. The implementation of an international tradable permits system would probably be facilitated if domestic systems have already familiarized local stakeholders with the permits approach (by the early identification of marginal abatement costs, and also by facilitating the eventual establishment of monitoring and control systems at the international level). In short, 
considerable potential exists for a wider use of the tradable permits approach, both nationally and internationally. The key challenge now is to realize that potential. 


\section{APPENDIX I. COUNTRY EXPERIENCES WITH ENVIRONMENTAL TAXES: THE ECOTAX LEADERS}

\section{A. Environmental Tax Reform in Denmark}

Environmental concerns became the focal point of the tax policy discussions in Denmark around 1990 when Denmark passed an energy action plan with the objective of reducing the level of emissions of $\mathrm{CO}_{2}$ by 20 percent in 2005 compared to the level in 1988 (Helbo Hansen, 1999). Furthermore, Denmark acceded to the EU agreement for emissions in the . year 2000 not to exceed their level in 1990.

The action plan was followed up by three important tax reform initiatives:

1. In 1992-93, a $\mathrm{CO}_{2}$ tax was introduced at a level of about US\$17 per ton of $\mathrm{CO}_{2}$, initially only on households, but later extended to industry, followed by a reduction in the taxes on oil and gas. For households, the $\mathrm{CO}_{2}$ tax rate was about 20 percent of the consumer price net of taxes, in addition to the standard energy tax rate of 105 percent of consumer prices net of taxes. For reasons of competitiveness, industry paid only a rate of 10 percent, with reduced rates applied to energy-intensive industries (a degressive rate schedule was introduced with reference to the value added of industrial companies). Because the degressive rate schedule gave only limited incentive effects compared to the average tax burden on a company, the tax provisions were supplemented by a system of voluntary agreements through which eligible enterprises would be refunded all the tax if they carried out energy-saving programs, controlled though an independent audit. The extra revenue raised from this tax ( 0.2 percent of GDP) was in part used to increase energy saving expenditures, and in part to reductions on the tax on beer and wine (by some observers characterized as an interesting variation of the double dividend).

2. A major green tax reform was to be phased in during 1994-98, the main objective being a substitution of taxation on labor corresponding to about 2.2 percent of GDP (with marginal tax rates on labor to be reduced by 10 percent) by increased ecotaxes and charges on energy, waste, water, and sewage (1.2 percent of GDP), as well as by higher capital income taxes ( 1 percent of GDP). The overall reform was intended to be revenue neutral through "recycling" of the revenue gain back to industry, through lower social security contributions of employers and investment incentives to induce industrial energy-saving measures. The higher energy taxes initially only applied to consumers, but work was initiated to prepare higher energy taxes on industry as well.

3. This led to the introduction in 1996 of a tax on $\mathrm{SO}_{2}$ emissions of about US\$1.7 per $\mathrm{kg}$, as well as a further increase in the $\mathrm{CO}_{2}$ tax on businesses. Particularly the $\mathrm{SO}_{2}$ tax had a radical impact on consumption, since industry with relative ease could move consumption toward low-sulfur fuels. During the whole of this process there was an extensive activity in industry to introduce meters, and to negotiate individual agreements on pollution-reducing measures and plans. Considerations are under way to further increase green taxes and to broaden the scope of their use. Energy tax rates were further increased and new ecotaxes 
introduced during the fall of 1998, including in particular a new tax on nitrogen consumption outside agriculture, which was combined with comprehensive regulatory measures to restrict nitrogen use in agriculture. Interestingly, despite the arguments that regulation involves higher costs than economic instruments such as taxes, Danish farmers strongly opposed the tax route and argued in favor of regulation to reduce nitrogen emissions to the environment.

The overall macroeconomic impact and the impact on overall employment is expected to be modest, although the impact for individual sectors and industries may be quite significant.

\section{B. Environmental Tax Reform in Norway}

Since the late 1980s, a strong focus on sustainable development has become a cornerstone of policymaking in Norway (Moe, 1999). In this respect, Norway was clearly among the frontrunners with regard to devising ways to encompass environmental concerns in general economic policies, with the aim of achieving a high level of employment and growth without harming the environment. Today, Norway probably has the most extensive framework for environmental policy of all countries in the world. As just one element of this framework, an annual document annexed to the budget examines the environmental profile of the state budget, identifying all expenditure items that are wholly or partly motivated by environmental policy objectives.

While environmental legislation in general has a fairly long history in Norway, environmental tax policy moved to the mainstream of policymaking only in the late 1980s. Based on the recommendations of an early environmental tax commission established in 1990 , a number of environmental taxes and charges were put in place in subsequent years inter alia with the aim of stabilizing $\mathrm{CO}_{2}$ emissions in the year 2000 at 1989 levels. It was calculated that achieving this ambitious goal would inevitably have negative consequences for employment. The key policy instrument was the $\mathrm{co}_{2}$ tax introduced in 1991 with different rates for different fossil fuels. A number of tax exemptions, mainly for export-oriented manufacturing industries, mean that only about 60 percent of total $\mathrm{CO}_{2}$ emissions are subject to the tax, and only about 20 percent of emissions from manufacturing. The exempt manufacturing sectors-similar to the situation in the other countries with a $\mathrm{CO}_{2}$ tax-are heavily exposed to international competition.

A broad-based second environmental tax commission established in 1994 submitted its report to the government in 1996. A key objective of the commission was to design policies to ensure that the economy can deliver both high employment and a better environment, and the approach adopted was to seek ways to integrate environmental policies and objectives in mainstream macroeconomic policies. Core to the work of the commission were the questions

of whether taxes on labor could be relieved and replaced with incentive-based green taxes, and the possible implementation strategies for such a reform in a small open economy. A key issue in this regard was also the cost effectiveness in reducing national $\mathrm{CO}_{2}$ emissions in accordance with the binding commitments reached in Kyoto in December 1997. In this respect, Norway was one of the only five countries that implemented a carbon tax to curb 
$\mathrm{CO}_{2}$ emissions, which in 1996 accounted for 70 percent of total greenhouse gas emissions in Norway.

Based on fairly extensive empirical research and a large number of simulations, the commission concluded that taxes on labor and on investment are the most distortive at the margin, and that environmental taxes, set correctly, can improve the efficiency of the economy. Substituting the one with the other would represent win-win policies. Despite these clear but theoretical advantages, the commission also pointed to a number of drawbacks of such a policy. For instance, labor taxes in the form of payroll taxes and social security contributions constitute an important and stable revenue source; and structural changes of a nature and range required would lead to opposition from the groups and sectors adversely affected.

The model simulations carried out by the commission, which illustrates the effect of raising green taxes by 1 percent of GDP with a broadly offsetting reduction in payroll taxes, showed a marginally positive effect on key macro variables (disposable income, inflation, employment, and unemployment), combined with significant environmental benefits. On the key question of whether green tax reform may produce a double dividend, the commission points to the theoretical a priori inconclusiveness, but also--through its empirical simulations-seems to underpin the view that a double dividend will, in fact, materialize over the long term, if reforms are correctly designed, although the effects in long term equilibrium may be modest. It should be stressed, though, that in the view of the commission, a double dividend is not a necessary condition for carrying out reforms, as long as the policies benefit the environment without hurting employment, or strengthen employment and the efficiency of the economy in general without affecting the environment negatively.

Empirical research suggests that the $\mathrm{CO}_{2}$ taxes in Norway may have reduced emissions by about 3 to 4 percent in 1991-93. However, the above-mentioned commissions pointed to the need to raise the effectiveness of the carbon tax structure: hence, the exemptions and the weak link between the rates of taxation and the carbon content of products imply that the incentives for reducing carbon emissions are weakest in industries where marginal abatement costs are lowest. The majority of the latter commission, therefore, advocated a rapid change to a carbon tax system without exemptions. A governmental proposal of April 1998, to extend the carbon tax to exempted sectors (with compensations) met fierce opposition in parliament, and was eventually watered down, with the new $\mathrm{CO}_{2}$ taxes coming into effect as of January 1999. Parliament decided in this connection to set up a commission to prepare a national system of tradable emission quotas for mainland processing industries, linked to the Kyoto mechanisms, with a report ready by the end of 1999 . According to a Ministry of Finance estimate, the introduction of international emission trading may significantly reduce the annual abatement costs of compliance with the Kyoto targets compared to national solutions, to as much as a third (from 0.6 to 0.2 percent of GDP). 


\section{Environmental Tax Reform in Sweden}

The comprehensive tax reform of 1991 signaled a major shift in the emphasis of environmental policies in Sweden, from the previous extensive use of subsidies to achieve environmental objectives, toward the use of taxes as the main economic instrument (Brannlund, 1999). The 1991 reform was in part based on the work of a Commission on Environmental Charges set up as early as in 1988. The overall reform was based on a significant reduction in income taxes, largely offset by a series of new ecotaxes, especially on carbon, sulfur, and nitrogen oxides by a restructuring of energy taxation and by a broadening of the VAT base. The net effect was a 6 percent redistribution of GDP, including about 1 percent related to ecotaxes. A key element in the green tax reform was the introduction as of January 1, 1991 of a $\mathrm{CO}_{2}$ tax on oil, coal, and natural gas. Following a second round of reform in 1993, the manufacturing sector pays only 25 percent of the tax for reasons of competitiveness. The initial intention (but later abolished) was to stabilize $\mathrm{CO}_{2}$ emissions at the 1988 level. It was estimated that environmental and environmentally related taxes in Sweden in 1996 yielded about 3.2 percent of GDP or 6 percent of total tax revenues.

In the spring of 1995, a new commission, the Green Tax Commission, was established to analyze the scope for using taxation to improve environmental quality and at the same timeas a second dividend--achieve a more efficient resource allocation through a reduction in unemployment. The commission was given a very broad terms of reference, including the effect on the environment, employment, industrial competitiveness, and revenue yields. While no specific reform was suggested, the commission offered some principles to guide future policies including a more proactive effort in international fora to combat global and regional environmental problems, and increased efforts regarding research, including in the EU and Nordic contexts. Recommendations also included increased attention to the equity aspects of ecotaxes and the need in general to avoid earmarking. An important conclusion of the Commission's work is that increase in green taxes cannot be expected to yield revenues of a level, which could finance substantial reductions in labor taxes. Hence, any revenue gains should be allocated carefully and selectively.

The work of the commission also included useful analysis of key questions, mainly based on general equilibrium (GE) models, such as the existence of a double dividend: the final report points to the fact that recent literature (e.g., Oates, 1995) questions the existence of a double dividend with reference to the fact that the green taxes by themselves are distortionary, and that these distortions may well outweigh the benefits of reducing other distortionary taxes such as taxes on labor. The GE-model simulations undertaken by the commission indicate that a tax reform comprising a 100 percent increase of the $\mathrm{CO}_{2}$ tax and a revenue-neutral reduction of labor taxes is likely to have a negative welfare effect on Swedish households, environmental effects excluded. In other words, there is no double dividend. Other interesting results of the analyses carried out by the commission includes simulations of the distributional consequences of the reform showing that $\mathrm{CO}_{2}$ taxes are somewhat regressive.

The Swedish draft budget for 2000 calls for a number of green-tax increases which in part will fund employment measures, including through job skill training. 


\section{Environmental Tax Reform in the Netherlands}

Introduction of green taxes in the Netherlands dates back to 1988 when a new fuel charge replaced a fragmented system of earmarked levies (Zom, 1999). The fuel charge was transformed in 1992 into a general fuel tax with the financing responsibilities for environmental expenditures at the same time being shifted to the general budget. This marked the start of a more comprehensive tax reform effort based on the introduction of green taxes.

By 1996, five distinct environmental taxes had been introduced (tax on the extraction of ground water, tax on waste disposal, fuel tax, tax on uranium, and the regulatory energy tax) with a total yield corresponding to about 1.8 percent of total taxes in that year, subsequently reaching about $2 \frac{1}{2}$ percent in 1998 .

While an important objective of the first four taxes was to raise revenue, in addition to their obvious environmental policy motives, the regulatory energy tax was somewhat different. The dual objective of this tax was, first, to provide financial incentives for energy conservation and the reduction of $\mathrm{CO}_{2}$ emissions and, second, to enable an efficiency enhancing restructuring of the tax system from direct taxes, particularly on labor toward environmentally related taxes. A special feature of this tax is a volume ceiling on the use of taxable energy which contributes to focus the tax on small users of energy (households and small commercial establishments) which are often thought to be the most difficult group to reach through other policy instruments (such as permits); simultaneously, the tax avoids the adverse effects on international competitiveness that would follow from taxes on large industrial enterprises. The rate and base of the tax is in line with the 1992 proposal for a European Union directive for a $\mathrm{CO}_{2}$ /energy tax, with half of the tax base related to carbon content and the other half to energy content.

These initiatives on the indirect tax side (i.e., consumption taxes) have been supplemented during the 1990s with important reform measures on the direct taxes (i.e., income taxes), primarily through the introduction of tax incentives to promote environmentally friendly investments (free depreciation on environmental investment; tax relief for benefits from green investments; and an energy investment tax credit).

In March 1995, a Green Tax Commission was established in the Netherlands with the purpose of evaluating the practical possibilities for using taxes to improve environmental quality and sustainable economic development. The Commission, which has applied a tax-by-tax approach to its assessment, adopted a list of fairly strict criteria for evaluating potential green tax measures, including: demonstrable environmental benefits; consistency with international law; simplicity of implementation; absence of adverse effects on the economy as a whole; and broad revenue neutrality. In addition, according to the commission, green taxes should not be applied to behavior that should not or cannot be changed to avoid the taxes. Some of the commission's proposals have already been implemented in practice. The commission's third and last report dealt with the potential for further greening 
the Dutch tax system in a long-term perspective, inter alia, by shifting further from direct to indirect taxes.

The Dutch approach to green tax reform is somewhat different in its careful emphasis on "greening" the existing tax system rather than, as the main approach used in most other countries, basing the green tax reforms mainly on the introduction of new types of taxes. 


\section{ApPendix II. Country EXPeriences with Tradable Permits Systems}

\section{A. The United States Experience}

\section{The United States emission-trading program}

As an instrument of abatement policy, tradable permits were used for the first time in 1975 by the Environmental Protection Agency (EPA) through its Offset Program for air pollutants. Interestingly, the program arose from an attempt to implement strict emission regulations, . which in many areas could not be met within the timetable or could be met only at substantial opportunity cost in terms of forgone economic growth. By 1975, it had become clear that a number of regions, designated as "nonattainment" regions by the Clean Air Act, would fail to attain the ambient air quality standards by the deadlines mandated in the Act. The Offset program was an attempt by EPA to improve air quality while fostering economic growth as well. The program worked as follows. New firms were allowed to enter nonattainment regions provided that they acquired sufficient emission-reduction credits (representing excess reduction) from other facilities in the region so that total regional emissions would be lower after entry than before. This was accomplished by requiring new sources to secure credits for 120 percent of the emissions they would add, the extra 20 percent being retired as an improvement in air quality.

The program evolved over a number of years and eventually led to the 1986 Emissions Trading Policy Statement, which covers several pollutants such as carbon monoxide, sulfur dioxide, particulates, volatile organic compounds (VOCs) and nitrogen oxides. The program is characterized by several elements. The geographic "netting" or "bubble" element allows trade of emission reductions among different sources within a firm, as long as the combined emissions under the bubble are within the allowable limit. The "offset" element allows firms to trade emission credits between existing and new sources as long as the new emissions are more than offset by a reduction from existing sources. Finally, the "banking" element allows firms to accumulate and store emission-reduction credits for future use or sale. Overall, the program is assessed as successful both in terms of environmental effectiveness and economic efficiency, despite certain weaknesses, which have limited participation and interfirm trading.

\section{The lead-in-gasoline program}

Following the path set by the offset program, the government began applying the tradable permits approach more widely. One prominent use involved facilitating the regulatory process for getting lead out of gasoline. Under this program set up in 1982, a fixed number of lead rights (authorizing the use of a fixed amount of lead over the transition period) were allocated to the various refiners. Refiners who did not need their full share of authorized rights (due to early compliance) could sell their rights to other refiners. Refiners had an incentive to eliminate the lead quickly because early reductions freed up rights for sale. Acquiring these credits made it possible for other refiners to comply with the deadline. Designed purely as a means of facilitating the transition to this new regime, the lead-banking 
program ended as scheduled on December 31, 1987. Two features of the program are noteworthy. First, it resulted in a much easier phaseout of lead than would have traditionally be possible because of the interrefinery flexibility that it offered (Tietenberg, 1998). Second, the program was designed to eliminate a pollutant not merely to place an upper limit on its annual use. In that respect, the program was rather unique.

\section{Trading of permits for water pollution control}

Tradable permits programs have also been used in the United States to control water pollution. The two most notable cases are: (1) the Wisconsin Fox River water permits for point pollution sources; and (2) the Colorado Dillon Reservoir water permits for nonpoint pollution sources. In 1981, the State of Wisconsin issued discharge permits to 14 paper mills and 4 waste water treatment plants discharging effluents into the Fox River. The permits were issued only for reduction in BOD discharges exceeding the levels required by treatment standards. Trading was allowed to give firms more flexibility in controlling and treating their effluents. Despite estimates of potential cost savings of up to US\$7 million per year, only one trade has taken place (Smith and Vos, 1997) under the program. The reason most frequently cited to explain this lack of trade is the oligopolistic structure of the pulp and paper industry and the regulated public utility status of the wastewater treatment plant which limited competition (Panayotou, 1998).

Under the permits trading program between point and nonpoint pollution sources at the Dillon Reservoir in Colorado, point sources are allowed to treat their effluents at less than required (drinking water) standards in exchange for treatment of nonpoint pollution sources. In this case, the point sources are publicly owned sewage treatment plants, and the nonpoint sources are agricultural, recreational, and urban activities. The fact that trading in this system is between the waste treatment facilities and the water authorities implies low transactions costs and hence easier implementation. Despite some estimates of cost savings of approximately US\$1 million a year (Hahn and Stavins, 1991), only one point/nonpoint source trade and a few nonpoint source trades have taken place since the program's inception in 1984. Hahn and Hester (1990) attribute this dearth of trades to the requirement of prior government approval.

\section{The $\mathrm{SO}_{2}$ allowance program}

More recently, EPA has employed a tradable permits system to control acid rain. Under the program, $\mathrm{SO}_{2}$ allowances have been allocated freely to existing sources based on baseline fuel use and a specified emission rate; the number of allowances will then be restricted to two phases to assure reduction of 10 million tons in emissions from 1980 levels by the year 2010 . To comply with the program, each existing firm must hold allowances equal or greater than their emissions during the year. Allowances can be traded within and between utilities as well as banked for future use. Firms found to produce excess emissions pay a penalty of $\$ 2,000$ per ton and are required to offset their excess the following year. Except for monitoring compliance, EPA's involvement in the program was minimal. For this reason, it is said to have worked better than earlier programs. Other reasons often attributed to the 
program's success are the existence of monitoring technologies for $\mathrm{SO}_{2}$ and the mandatory requirements for firms to install continuous emission monitors. The first phase of emissions reduction was achieved in 1995 and applied only to the most emission-intensive generative units. Under Phase II of the program (to begin in year 2000), all fossil fuel power plants will be included. So far, the program seems to have worked very well, achieving and exceeding the targeted emission reductions. More than four million tons of allowances were transferred in 1996 between independent plants (Panayotou, 1998).

\section{The post-Montreal CFCs trading system}

Through the Montreal Protocol which 24 nations signed in September, 1988, and, later on, the London Conference which 59 nations signed in July 1990, signatory nations agreed to restrict their production and consumption of the chief gases responsible for the depletion of the ozone layer in order to eventually achieve a complete phase out of these gases between the years 2000 and 2005. To implement its responsibilities under the protocols, the United States has chosen to use a transferable permits system. In August 1988, the EPA issued regulations implementing a tradable permits system to achieve the targeted reductions. According to these initial regulations, all major U.S. producers and consumers of the controlled substances were allocated baseline production and consumption allowances using 1986 levels as the basis for proration. Each producer and consumer is allowed 100 percent of this baseline allowance initially, with smaller allowances being granted after predefined deadlines. These allowances are transferable within producer and consumer categories and allowances can be transferred across international borders among signatory nations if the transactions are approved by EPA and results in the appropriate adjustments in the buyer or seller allowances in their respective countries ${ }^{22}$. Production allowances can be augmented by demonstrating the safe reduction of an equivalent amount of controlled substances by approved means. Some interpollutant trading is even possible within categories of pollutants. All information on trades is confidential, so it is difficult to know how effective this program has been. One estimate suggests that as of September 1993, the traded amount was roughly 10 percent of total permits (Hahn and Stavins, 1991). It was also suggested that by allocating allowances to the major domestic producers of CFCs and halons, EPA created sizable windfall profits (estimated to be in the billions of dollars) for those producers (see Tietenberg, 1998). These windfall profits were then taxed away by the United States Congress.

\section{States' initiatives}

While all of the above programs were initiated and promoted by the federal government, the newest programs have arisen from state initiatives. One of the most ambitious of these programs is California's RECLAIM program of the South Coast Air Quality Management District of Southern California. This program was initiated in 1992 and covers trading in $\mathrm{SO}_{2}$

${ }^{22}$ Very few cases of such international trades have been reported to this date. 
and $\mathrm{NO}_{\mathrm{x}}$. Tradable permits were issued to 2,700 large polluters in proportion to the pollution emissions they would produce in 1992 at full production capacity. The number of permits issued annually will be reduced 8 percent annually for $\mathrm{NO}_{\mathrm{x}}$ and 6 percent annually for $\mathrm{NO}_{2}$ until the entire region is in full compliance with federal ambient standards. Trading is allowed and encouraged. Several brokerage firms are involved in making markets. The district has estimated savings of at least US $\$ 270$ million per year over previous programs (Howe, 1994).

Another example is the Ozone Transportation Commission (OTC) initiative to control $\mathrm{NO}_{x}$ emissions. In 1994, a group of North-Eastern states participating as members of the OTC, committed themselves to achieving region-wide $\mathrm{NO}_{\mathrm{x}}$ emission-reduction targets by 1999 and 2003 through a tradable permits system. The $\mathrm{NO}_{\mathrm{x}}$ budget program is a "cap-and-trade" program that allows large emitters of $\mathrm{NO}_{x}$ emissions to trade allowances to meet the emission targets in a cost-effective manner. Since the multistate committees that negotiated the agreements had no statutory authority, a model rule was developed to serve as a template for state laws that must be enacted for each state to participate. Elements covered by the model rule include: program applicability, control period, emission limitations, emission monitoring, record keeping, and electronic reporting equipment. Each state has now the responsibility for developing and adapting state rules that are consistent with the model rule, and a number of states have already done so. The first phase of the program was due to start in May 1999 with an initial cap of 219,000 tons per year per region. This cap will remain in place until 2003, the start of the second phase, when the cap will be reduced to 143,000 tons. The United States experience with tradable permits has stimulated interest in many countries. Yet, there has been rather limited experimentation in other countries either developed or developing, although serious considerations to this effect are being made.

\section{B. Experience in Other Developed Countries}

\section{The European experience}

The major EU countries have long made extensive use of an array of pollution taxes (as described in the previous section) but have rarely used tradable-permits schemes. The few applications that do exist are briefly mentioned below. In Germany, the air pollution legislation allows the transfer of emission-reduction obligations (offset) but this possibility is reported to have been used in less than 2 percent of the cases (OECD, 1997a). In the Netherlands, power plant bubbles are allowed under an agreement signed between the 12 provinces and the Association of Electric Producers in 1990. In the United Kingdom, provisions for intrafirm bubbles for power plants have been introduced in 1996. While provisions have been introduced for pollution trading in these countries, OECD (1997a) argues that the systems have been applied on a very limited scale.

\section{The Australian and New Zealand case}

Tradable permits have been used on a somewhat greater scale in Australia and New Zealand. In Australia, the Murray-Darlin Basin Commission's program for salinity abatement of 
agricultural land and river system, began on January 1, 1988, as the "Salinity and Drainage Strategy." The strategy requires the state governments to desalinate the river Murray so as to reduce salinity by approximately 113 electric currents $(E C)^{23}$ by 2015 . As a reward for such reductions, each state government receives salinity credits and may then choose to allow persons to resalinate the river, by selling or issuing their credits. It is estimated that after credits have been issued, river salinity would improve by approximately 78 EC (Australian Bureau of Industry Economics, 1992).

Tradable permits systems have also been used both in Australia and New Zealand in a slightly different context, namely, fisheries management. ${ }^{24}$ Tradable permits (referred to, in the context of fisheries management, as individual transferable quota or ITQ) provide individuals with rights to harvest up to a given quota of the fish stock. The sum of all the quotas is the Total Allowable Catch (TAC) which is also the maximum yield consistent with the survival of the species. These permits are tradable between vessels. They are denominated in tons of catch per fishing year (of the specified fishing stock). Numerous ITQ systems have been used in Australia and abroad. One of the most notable ones, the tripartite (Australia, New Zealand, and Japan) Southern Bluefin Tuna (SBT), failed from two main reasons allegedly: (1) authorities consistently failed to measure the true size of the population stock; and (2) population growth was volatile and unpredictable, thereby placing the stock at risk of over harvesting. A much wider application of tradable quotas is New Zealand's Quota Management Scheme (QMS). Concern has been raised with regard to its operations because of an apparent failure to reach an adequately stable and unique price for quotas. It was argued that trades had not been active enough to generate sufficient observations for reliable analysis (Australian Bureau of Industry Economics, 1992). Despite this problem, many believe that to this day New Zealand has been the most effective country in imposing this type of system (Panayotou, 1998).

\section{Experience in developing countries}

As yet, there has been no survey of the use of MBIs in developing countries comparable to those done for OECD countries. Only two major instances of operational tradable permits were reported in the still limited reviews of the literature on environmental policy in developing countries (O'Connor, 1998, OECD, 1997a, and Panayotou, 1998): in Chile and in Singapore.

${ }^{23}$ Electric currents are a standard measure of salinity and are used in calculating the number of salinity credits available for trade.

${ }^{24}$ Other countries such as Canada, Iceland, the Netherlands, and the United States have experimented with such programs, but on a much smaller scale. 


\section{Chile's 20-year experience with tradable water rights}

Under Chile's water policy, individuals are granted freely tradable water use rights which are defined for a fixed quantity per unit of time and are awarded following application by a potential user. A water right is granted provided that it does not impair existing rights and that the ecological requirement of minimum flow has not yet been reached by previous allocations. These rights are granted free of charge and recorded in a national register, the granting authority reserving the rights to restrict water consumption in time of shortage. While owners of consumptive rights (e.g., irrigation mainly) have no specified obligation . with regard to quality and quantity of return flows, owners of nonconsumptive rights (e.g., hydropower and recreation) are required to return the same quantity and quality of water. Water rights are freely tradable and the market for water rights is reported to be quite active (Panayotou, 1998).

\section{Singapore's experience}

Singapore's CFC permits auction scheme began in the late 1980s, after the ratification of the Montreal protocol. Each quarter the national consumption quota was allocated among importers and users, half on the basis of historic consumption (grandfathering) and half through auction. Importers and users were required to register to participate in the bidding process, with each firm specifying the amount of its demand and its bid price. Bids were ranked by price, with the lowest winning bid price (the one just exhausting the stock) serving as the unit permits price. That price was then charged on the full national allotment. Initially, there was a steep increase in permits price, providing users with incentives to adopt conservation measures, substitutes, and alternative technologies. As a result, $\mathrm{CFC}$ demand fell sharply. Since the decline in demand depressed the price, the government accelerated the phase-out schedule in an effort to support the price and maintain the incentive for continued demand reductions.

Singapore has also devised a vehicle ownership quota system designed to limit the growth in supply of private automobiles. The Vehicle Quota System (VQS) was introduced in May 1990 , following essentially the same principles as the CFC quota system. Under VQS, anyone wishing to own a vehicle (except for buses and emergency vehicles) must have a certificate of entitlement (COE). Those vehicles already registered at the inception of the system were assumed to have a $\mathrm{COE}$ (another instance of grandfathering), while anyone wanting to buy a new one is required to bid for a $\mathrm{COE}$ in monthly tendered exercises. Each bidder must indicate the amount he or she is willing to pay for the right to own a vehicle in a particular category. Bids are ranked from highest to lowest; each successful bidder pays a COE price equal to the lowest successful bid price. The COE is valid for ten years from the date of registration of the vehicle, after which the COE must be renewed at the prevailing price defined as the 12-month moving average price of the COE in that vehicle category. By mid-1992, the COE price for a standard car had risen by more than 60 percent and represented about one-quarter of the total sale price (Panayotou, 1998). 


\section{References}

Australia, Bureau of Industry Economics, 1992, The Economics of Tradable Permits-A Survey of Theory and Practice (Canberra: Australian Government Publishing Service).

Baumol, W., and W. Oates, 1988, The Theory of Environmental Policy (New Jersey: Prentice Hall).

Bohm, P., and C. Russell, 1985, "Comparative Analysis of Alternative Policy Instruments," in Handbook of Natural Resource and Energy Economics, ed. by A. Kneese and J. Sweeney, Vol. 1 (Amsterdam: North-Holland).

Bovenberg, A., and R. de Mooij, 1994, "Environmental Levies and Distortionary Taxation," American Economic Review, Vol. 84, pp. 1085-89.

Brannlund, R., 1999, "Green Tax Reforms: Some Experiences from Sweden," in Green Budget Reform in Europe: Countries at the Forefront, ed. by $\mathrm{K}$. Schlegelmilch (Berlin; New York: Springer-Verlag).

Buchanan, J., 1969, "External Diseconomies, Corrective Taxes and Market Structure," American Economic Review, Vol. 59, pp. 139-47.

Burrows, P., 1981, "Controlling the Monopolistic Producer: Nihilism or Eclecticism," Journal of Environmental Economics and Management, Vol. 8, pp. 372-80.

Ellerman, D, P. Joskow, and R. Schmalensee, 1996, "Update on Compliance and Emissions Trading under the U.S. Acid Rain Program," CEPR Working Paper (Cambridge, Massachusetts: Massachusetts Institute of Technology).

Endres, A., 1997, "Incentive-based Instruments in Environmental Policy: Conceptual Aspects and Recent Developments," Konjunkturpolitik: Zeitschrift Fur Angewandte Wirtschaftsforschung, Vol. 43 (No. 4), pp. 299-343.

Goulder, L., 1995, "Environmental Taxation and the Double Dividend: A Reader's Guide," International Tox and Public Finance, Vol. 2, pp. 157-84.

Hahn, R., 1989, "Economic Prescriptions for Environmental Problems: How the Patient Followed the Doctor's Orders," Journal of Economic Perspectives, Vol. 3, pp. 95-114.

Hahn, R., and G. Hester, 1990, "Where did all the Markets Go? An Analysis of EPA's Emissions Trading Programs," Yale Journal of Regulation, Vol. 7, pp. 109-53. 
Hahn, R., and A.M. McGartland, 1989, "The Political Economy of Instrument Choice: an Examination of the U.S. Role in Implementing the Montreal Protocol," Northwestern University Law Review, Vol. 83 (No. 3), pp. 593-611.

Hahn, R., and R. Stavins, 1991, "Incentive-Based Environmental Regulation: A New Era from an Old Idea?" Ecology Law Quarterly, Vol. 18, pp. 1-42.

Harrison, D., 1999, "Tradable Permits for Air Pollution Control: The U.S. Experience," in Implementing Domestic Tradable Permits for Environmental Protection, proceedings of an OECD Workshop (Paris: Organization for Economic Cooperation and Development).

Helbo Hansen, J. H., 1999, "Green Tax Reform in Denmark," in Green Budget Reform in Europe: Countries at the Forefront, ed. by K. Schlegelmilch ((Berlin; New York: Springer-Verlag).

Helfand, G., 1999, "Controlling Inputs to Control Pollution: When Will it Work?" $A E R E$ Newsletter, Vol. 19 (No. 2), pp. 13-17.

Howe, C., 1994, "Taxes versus Tradable Discharge Permits: A Review in Light of the U.S. and European Experience," Environmental and Resource Economics, Vol. 4, pp. 151-69.

Joskow, P., and R. Schmalensee, 1998, "The Political Economy of Market-Based Environmental Policy: The U.S. Acid Rain Program," Journal of Law and Economics, Vol. 41, pp. 89-135.

Klaassen, G., 1996, "Emission Trading for Air Quality Standards: Opening Pandora's Box?" paper presented at the Seventh Annual Conference of the European Association of Environmental and Resource Economists (EAERE) Lisbon, Portugal, June 27-29.

Klaassen, G., and A. Nentjes, 1997, "Sulfur Trading Under the 1990 CAAA in the U.S.: An Assessment of First Experiences," Journal of Institutional and Theoretical Economics, Vol. 153 (No. 2), pp. 384-410.

Koustaal, P., 1997, Economic Policy and Climate Change: Tradable Permits for Reducing Carbon Emissions (Cheltenham, U.K.: Edward Elgar).

Lyon, R., 1982, "Auctions and Alternative Procedures for Allocating Pollution Rights," Land Economics, Vol. 58 (No. 1), pp. 16-32.

Malueg, D., 1990, "Welfare Consequences of Emission Credit Trading Program," Journal of Environmental Economics and Management, Vol. 18, pp. 66-77. 
McMorran, R., and D. Nellor, 1994, "Tax Policy and the Environment: Theory and Practice," Working Paper No. 106 (Washington: International Monetary Fund).

Misiolek, W., and H. Elder, 1989, "Exclusionary Manipulation of Markets for Pollution Rights," Journal of Environmental Economics and Management, Vol. 16, p. 156-66.

Moe, T., 1999, "Policies for a Better Environment and High Employment," in Green Budget Reform in Europe: Countries at the Forefront, ed. by K. Schlegelmilch (Berlin; New York: Springer-Verlag).

Oates, W., 1992, "Pollution Charges as a Source of Public Revenues. Quality of the Environment Division," Discussion Paper No. 5, (Washington: Resources for the Future).

—, 1995, "Green Taxes: Can We Protect the Environment and Improve the Tax System at the Same Time?" Southern Economic Journal, Vol. 61 (No. 4).

—_ 1999, "Forty Years in an Emerging Field: Economics and Environmental Policy in Retrospect," Resources, Issue 137 (Fall), pp. 8-12.

O'Connor, D., 1998, "Applying Instruments in Developing Countries: From Theory to Implementation," Environment and Development Economics, Vol. 4, pp. 91-110.

Organization for Economic Cooperation and Development, 1995, Environmental Taxes in OECD Countries (Paris: OECD).

$\longrightarrow$ 1996, Implementation Strategies for Environmental Taxes (Paris: OECD).

—_ 1997a, Applying Market-based Instruments to Environmental Policies in China and OECD Countries (Paris: OECD).

—_- 1997b, Environmental Taxes and Green Tax Reform (Paris: OECD).

$-1999 \mathrm{a}$, Consumption Tax Trends, (Paris: OECD).

- 1999b, Economic Outlook (Paris: OECD).

,- 1999c, Environmental Taxes: Recent Developments in China and OECD Countries, (Paris: OECD).

___ , 1999d, "Implementing Domestic Tradable Permits for Environmental Protection," proceedings of an OECD Workshop, Paris.

O'Ryan, R., 1996, "Cost Effective Policy to Improve Urban Air Quality in Santiago, Chile," Journal of Environmental Economics and Management, Vol. 31, pp. 302-13. 
Panayotou, T., 1998, Instruments of Change: Motivating and Financing Sustainable Development (London: Earthscan).

Parry, I., 1995, "Pollution Taxes and Revenue Recycling," Journal of Environmental Economics and Management, Vol. 29, pp. 64-77.

Pigou, A. C., 1920, The Economics of Welfare (London: Mcmillan and Co., $1^{\text {st }}$ ed.).

Polesetsky, M., 1995, “Will a Market for Air Pollution Clean the Nation's Dirtiest Air? A Study of the South Coast Air Quality Management District's Regional Clean Air Incentives Market," Ecology Law Quarterly, Vol. 22, pp. 359-411.

Requate, T., 1993, "Pollution Control in a Cournot Duopoly via Taxes or Permits," Journal of Economics, Vol. 58, p. 255-91.

Sandmo, A., 1975, "Optimal Taxation in the Presence of Externalities," Swedish Journal of Economics, Vol. 77, pp. 86-98.

Smith, S., and H. Vos, 1997, Evaluating Economic Instruments for Environmental Policy (Paris: Organization for Economic Cooperation and Development).

Stavins, R., 1995, "Transaction Costs and Tradable Permits," Journal of Environmental Economics and Management, Vol. 29, No. 2, p. 133-48.

—, 1998, "What Can We Learn from the Grand Policy Experiment? Lessons from $\mathrm{SO}_{2}$ Allowance Trading," Journal of Economic Perspectives, Vol. 12, pp. 69-88.

Tietenberg, T., 1985, Emissions Trading: An Exercise in Reforming Pollution Policy (Washington: Resources for the Future).

$\longrightarrow$, 1998, "Tradable Permit Approaches to Pollution Control: Faustian Bargain or Paradise Regained?" (mimeo; Waterville, Maine: Colby College).

Weitzman, M., 1974, “Prices vs. Quantities," Review of Economic Studies, Vol. 41, pp. 447-91.

White, M., and D. Wittman, 1983, "A Comparison of Taxes, Regulation, and Liability Rules under Imperfect Information,” Journal of Legal Studies, Vol. 12, pp. 413-25.

Xepapadeas, A., 1997, Advanced Principles in Environmental Policy (Cheltenham, U.K.: Edward Elgar).

Zom, A., 1999, "Report on the Concrete Steps of Green Budget/Tax Reform in the Netherlands-Retrospective and Outlook," in Green Budget Reform in_Europe: Countries at the Forefront (Berlin; New York: Springer-Verlag). 